\title{
A strategy for producing refined currents in the Equatorial Atlantic in the context of the search of the AF447 wreckage
}

\author{
Marie Drévillon • Eric Greiner • Denis Paradis • \\ Christophe Payan • Jean-Michel Lellouche • Guillaume Reffray • \\ Edmée Durand • Stéphane Law-Chune • Sylvain Cailleau
}

Received: 15 September 2011 / Accepted: 24 October 2012 / Published online: 21 November 2012

(C) The Author(s) 2012. This article is published with open access at Springerlink.com

\begin{abstract}
On the night of 1st June 2009, a Rio-Paris Air France flight (AF447) disappeared in a highly variable and poorly observed part of the western tropical Atlantic Ocean. The first debris was located 5 days after the accident. Several reverse drift computations were conducted in order to define the likely position of the wreckage. Unfortunately, the performance of the operational ocean analyses available in the region of interest ranges from 80 to $100 \mathrm{~km}$ of positioning error after 5 days of inverse drift computation. In preparation of the third phase of research of the wreckage at sea, a series of numerical experiments was performed at Météo-France and Mercator Océan in an attempt to better compute the surface currents in the region and for the period of the accident of the AF447 (May and June 2009). Tailored high-resolution atmosphere and ocean reanalyses were first produced respectively at Météo-France and Mercator Océan. Several nested experiments were then performed with a small and flexible ocean model limited to the region of interest. The date of the initial conditions and the type of
\end{abstract}

\footnotetext{
Responsible Editor: Arthur Allen

This article is part of the Topical Collection on Advances in Search and Rescue at Sea

M. Drévillon $(\varangle) \cdot J .-M$. Lellouche $\cdot$ G. Reffray $\cdot$ E. Durand

$\mathrm{S}$. Law-Chune $\cdot \mathrm{S}$. Cailleau

Mercator Océan, Parc Technologique du Canal,

8-10 rue Hermès,

31520, Ramonville-St-Agne, France

e-mail:mdrevillon@mercator-ocean.fr

URL: http://www.mercator-ocean.fr

E. Greiner

CLS,

Ramonville-St-Agne, France

D. Paradis $\cdot$ C. Payan

Météo-France,

Toulouse, France
}

atmospheric forcing fields were varied in order to produce a small ensemble from which information on the sensitivity to these changes could be derived. Probabilistic and statistical combinations between model and observations were tested and a solution was finally selected by means of a comparison of drift computations with independent surface drift observations.

Keywords Operational · Currents · Drift · Ensemble · Positioning · Assessment

\section{Introduction}

\subsection{Location and circumstances of the accident}

On the night of 1st June 2009 at 0210 hours GMT, the Air France flight AF447 from Rio to Paris disappeared in the western Tropical Atlantic Ocean (Fig. 1). Its wreckage was not located then, and the first floating debris were sighted 5 days after the accident. From 10th June to 10th July 2009 (period hereafter called phase 1, see timeline in Fig. 2), several ships conducted acoustic searches to find the beacons. Reverse drift computations were performed by several searchand-rescue (SAR) groups in the world including the US Coast Guard and Météo-France. The drift computations were started from the debris found from 5th to 17th June, and their backward trajectory until the time of the accident was computed. The results indicated very different positions for the wreckage. All these likely positions were searched during phase 2 (from 27th July 2009 to 17th August 2009) using submarine robots. These two phases of search of the AF447 wreckage were both unsuccessful. The subsea search conditions were very difficult as the sea bottom is very deep (around 4,000 $\mathrm{m}$ ) in that region with a very rugged topography that can be compared with the Alps under 4,000 m of water as can be seen in Fig. 1. 


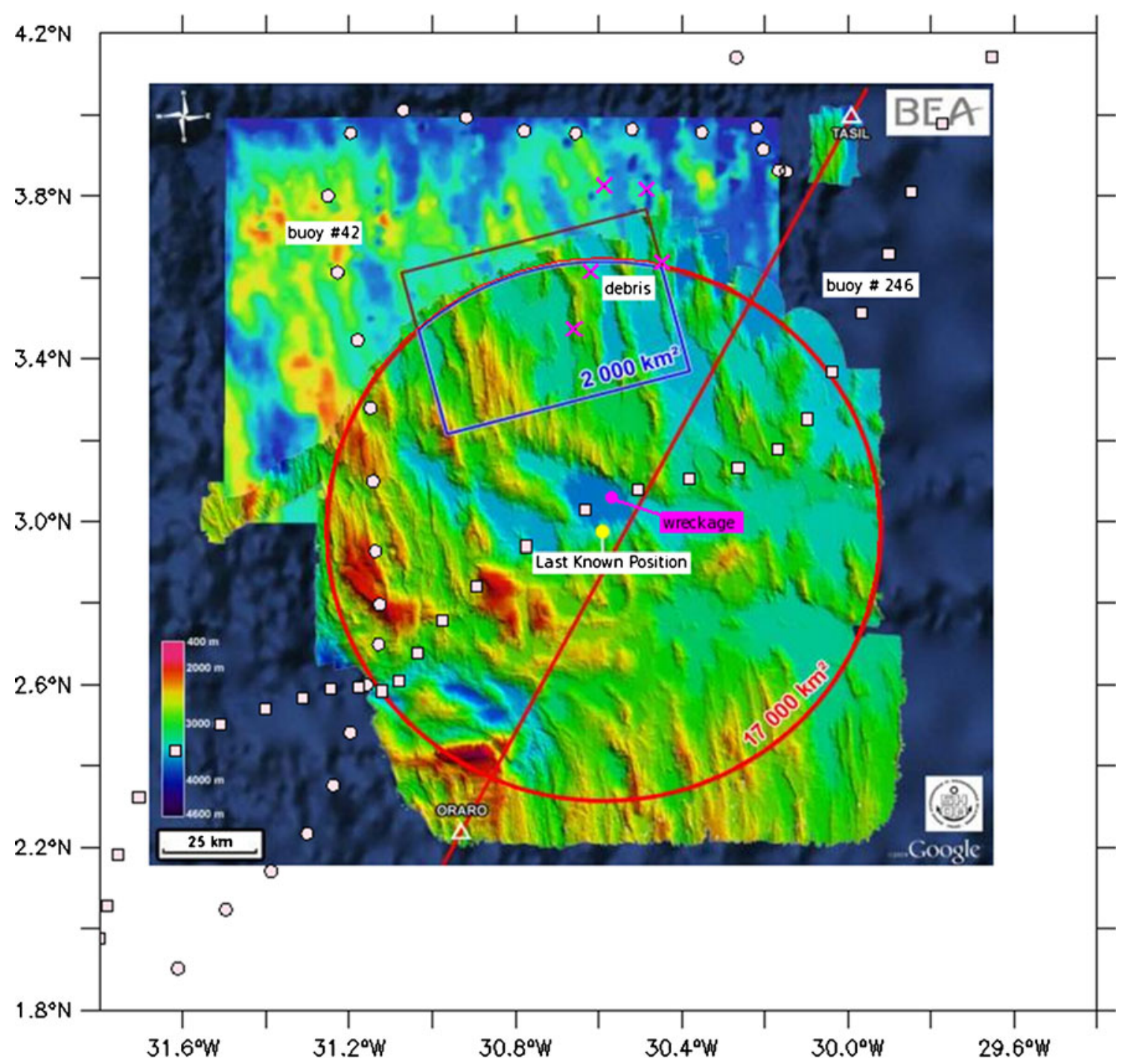

Fig. 1 Positions of the debris (magenta crosses) and fishermen buoys \#42 (circles) and \#246 (squares). The red line is the initial trajectory planned for the flight. The shading inside the $74-\mathrm{km}$ radius circle (red) around the LKP is the in situ bathymetry from SHOM (by courtesy of BEA, http://www.bea.aero/fr/enquetes/vol.af.447/ operations.de.recherches.en.mer.phase.3.php).
This region, near $3^{\circ} \mathrm{N}$ and $30^{\circ} \mathrm{W}$, is located in the atmospheric Intertropical Convergence Zone (ITCZ) and is subject to strong tropical storms. Ocean Tropical Instability Waves come from the east of the basin and travel westward into the western Tropical Atlantic Ocean. The onset of the eastward North Equatorial Counter Current, linked with the North Brazil current retroflection, begins in June-July and also influences this region near $4^{\circ} \mathrm{N}$ (see also, Scott et al. 2012 , for the description of the region). Satellite observations in tropical regions, and especially in the ITCZ, are often contaminated by rain (radars) and clouds (passive reflectance measurements). It was the case during the accident, when a very important convective cell took place that participated in the loss of the plane. This convective cell also contaminated wind, sea surface temperature (SST), and ocean colour satellite measurements. These difficult conditions partly explain the large uncertainties in reverse drift computations of phases 1 and 2. These drift computations backward in time are commonly used to find the initial position of a pollution, for instance. However, Breivik et al. (2012) demonstrate that other techniques such as multiple forward drifts (and selection of relevant drifts) can provide more valuable information. Eventually, the drift computations could not be properly validated without knowing the actual location of the wreck and without in situ current measurements close enough in space and time to the last known position (LKP) of the plane.

\subsection{Ocean currents and drift forecasts}

The input ocean currents were provided by Mercator Océan to Météo-France, and by the Navy Research Laboratory (NRL) 


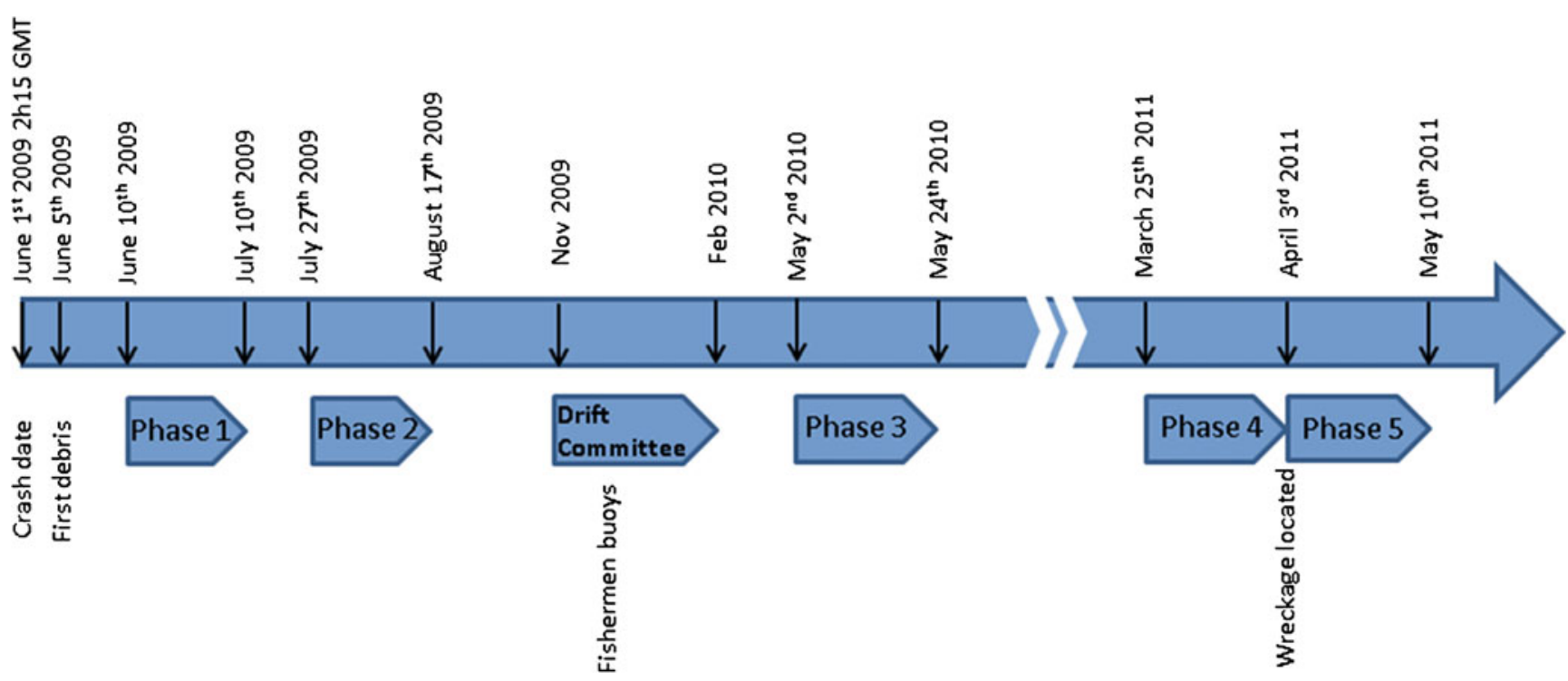

Fig. 2 Timeline of the search of the AF447 wreckage, from the accident in June 2009 to the final recovery of the wreck in May 2011

to the US Coast Guard. Analyses from two $1 / 12^{\circ}$ highhorizontal-resolution systems were used: the PSY2V3R1 regional system (North Atlantic and Mediterranean Sea) from Mercator Océan (hereafter referred to as PSY2) and the HYbrid Coordinate Ocean Model (Bleck 2002; Chassignet et al. 2006) HYCOM/NCODA global system from the NRL. These two systems are state-of-the-art operational ocean monitoring and forecasting systems (Dombrowsky et al. 2009). They were chosen to deliver information on the ocean currents at the time of the accident as they are known to be reliable in the Atlantic Ocean (Hurlburt et al. 2009). These ocean currents were then used by the SAR drift models Modèle Océanique de Transport d'HYdocarbures (MOTHY) of Météo-France (Daniel et al. 2002) and Search and Rescue Optimal Planning System of the US Coast Guard (O'Donnell et al. 2005), respectively. The analyses of PSY2 and HYCOM/NCODA ocean currents display differences, mainly at mesoscale (not shown). Those discrepancies suggest that ocean currents are a major source of uncertainty in the drift computations. Scott et al. (2012) showed that the performance of any of the available operational ocean current analyses in the region and season of interest was leading to positioning errors ranging from 80 to $100 \mathrm{~km}$ after 5 days of inverse drift computation. This level of uncertainty could not allow discriminating a sub-zone within the circle of radius $74 \mathrm{~km}(40 \mathrm{~nm})$ which was defined as the maximum area of search ${ }^{1}$ around the LKP of the airplane at $2^{\circ} 58.8^{\prime} \mathrm{N}$ and $30^{\circ} 35.4^{\prime} \mathrm{W}$.

Ocean forecasting is a young discipline, as most capacities were developed after 1992, the beginning of the

\footnotetext{
${ }^{1}$ Defined by the "Bureau d'Enquêtes et d'Analyses pour la sécurité de l'aviation civile" (BEA) as the maximum distance that the plane could have travelled under the circumstances.
}

altimetry era. An ocean monitoring and forecasting system is made of three major components which are the ocean model, the observations, and the data assimilation scheme. The model intrinsic errors and errors in the atmospheric forcing fields (and bathymetry, e.g. boundary conditions) generate large uncertainties. The lack of observations and/ or observational instrumental errors leads to poorly constrained analyses (initial condition errors). Finally, there are limitations in applying linear algebra of data assimilation schemes to a nonlinear geophysical fluid. While the agreement with temperature and salinity measurements is generally satisfactory, operational ocean analyses and forecast are only weakly correlated with the drifter velocity observations (of the order of 0.5 ). They generally underestimate the current variability (up to $20 \%$ underestimation), and the root mean square differences are on the order of 0.2 to $0.3 \mathrm{~m} / \mathrm{s}$ which means locally up to $100 \%$ relative errors (intercomparison results from Peter Oke, personal communication). These discrepancies can be associated with various causes: those systems do not assimilate yet the surface drifters' velocities, the surface layer is difficult to model and it has to be improved in the models in order to be able to do this data assimilation properly. One can also note that drifters may overestimate the currents in regions of strong winds due to the undetected loss of their drogues (Grodksy et al. 2011).

1.3 The importance of wind prediction and immersion rate

The wind predictions quality is a key factor in ocean drifts expertise, especially in the oceanic mixed layer where many multiscale ocean-atmosphere interactions take place (momentum exchanges, turbulence, and waves). Uncertainty in 
wind predictions are particularly crucial for this study as the movement of an object floating at the surface is subject to both ocean currents and winds, in proportions depending on its degree of immersion. The immersion rate of a floating object is the ratio of its immerged parts over its overall dimension in percentage. In addition to the advection by the ocean current, the drift velocity in terms of percentage of the wind (or windage) increases as the immersion rate decreases. This phenomenon is parameterised in MOTHY (see, Daniel et al. 2002). The immersion rate of the AF447 floating debris was not known during phases 1 and 2, giving rise to large uncertainties in the drift computations.

Previous studies on Lagrangian trajectories (for instance, Beg Paklar et al. 2008) or oil spill forecasts (Elliott 2004) have shown the importance of the quality of the wind stress on the realism of a drift forecast. In the atmosphere, the nonlinearity generates discrepancies with the observations with a smaller time scale than in the ocean. A homogeneous and high-resolution cover of observations is required in order to properly constrain the analyses that are performed at a high temporal frequency, every $6 \mathrm{~h}$ in the case of the Météo-France model Action de Recherche Petite Echelle Grande Echelle (ARPEGE). Rain contaminates satellite scatterometer measurements that allow constraining lowlevel wind in the atmosphere. Thus, in periods of strong convective events as during the AF447 accident, the wind analyses have intrinsically a lower quality.

Other processes related with the wind have to be considered as possible sources of uncertainty. The Stokes drift and the feedback of the ocean current on wind stress are important momentum exchange mechanisms at the ocean-atmosphere interface, and they were not taken into account by the Mercator Océan forecasting systems. In particular, the addition of the effect of the Stokes drift has shown a significant impact in reducing the errors of drift forecasts in several case studies (Law Chune 2012).

\subsection{Motivation of this work}

The BEA, which is the French authority in charge of investigating airplane accidents, decided in November 2009 to gather a group of ocean scientists and mathematicians in order to prepare the third phase of research that was to start in February 2010 and that finally took place from 2nd April to 24th May 2010. The group was asked to try new methods to reduce uncertainties in the drift computations, and finally to propose a search region for the beginning of phase 3 . The task was challenging as very little environmental information was available at the time. Moreover, the study had to be performed within a short delay ( 3 months) and only a few more observations were made available during this period. Ollitrault et al. (2010) present in detail the work that was done by the group of scientist hereafter called the "drift committee". In this article, we focus on the common effort of Météo-France and Mercator Océan as an attempt to better model surface currents and winds in the region and period of the accident of the AF447, and finally to improve the drift modelling accuracy. The few in situ measurements and satellite observations were not representative of the rapidly changing situation. Available satellite observations of the ocean were representative of a weekly average. New observational data were introduced in order to better constrain and/or validate those currents. Thanks to fishermen who agreed to provide their private observations as a gesture of solidarity, new surface current measurements were collected by Collecte Localisation Satellite (CLS) during the preparation of phase 3 . Some of these observations were particularly close to the LKP and were of crucial importance in this study. In order to define an area for the search, a mapping of the probability of presence of the wreck was proposed. The phase 3 was finally unsuccessful as the wreck was not found in the small research zone that was finally selected (blue rectangle on Fig. 1). However, we will show in this article that it was discovered in a region that the overall results indicated as probable.

The strategy and methodology chosen by Mercator Océan and Météo-France is first explained in Section 2. In Section 2.2.1, we point out two types of evaluation exercises that were performed using the ensemble of numerical experiments and with the buoys observations. In Section 2.3, several methods for combining the modelled currents and the observations are described. Methods to derive the likely locations of the wreckage are finally proposed. Results are discussed in Section 2.4, in the light of the discovery of the actual location of the wreckage in early 2011 .

\section{Objective and methodology}

\subsection{Methodology outline}

The main concern of this study for phase 3 was to improve as much as possible the atmospheric and ocean analyses, with a focus on surface winds and surface currents. The atmosphere and ocean operational analysis and forecasting systems could not be modified in a delay of 3 month. Experimental versions of the state-of-the-art systems were used for this purpose, and reanalyses were run for the period surrounding the accident (May and June 2009). This work was performed in autumn 2009 when it was possible to assimilate observations that were not yet available or properly controlled in June 2009. The reanalyses were performed separately with ARPEGE for the atmosphere (MétéoFrance) and PSY2 for the ocean (Mercator Océan) with a particular emphasis on the improvement of the ocean-atmosphere interface (surface winds and currents). 
Then, those reanalyses were used as boundary and initial conditions for several experiments with a flexible ocean model limited to a small domain centred on the region of interest. This $10 \times 10^{\circ}$ configuration of Nucleus for European Modelling of the Ocean (NEMO) (Madec 2008) could benefit from recent improvements of the ocean physics representation (mixed-layer scheme for instance). Some physical processes were added that are not yet taken into account in the global configuration such as tides and a high-frequency atmospheric forcing. Due to a relatively low computational cost, several experiments could be performed and validated (mainly against observed SST), and results could be obtained within a short delay. Moreover, it was possible to vary the date of the initial conditions (all coming from the optimised ocean analyses) and the type of atmospheric forcings. This small ensemble allowed us to derive information on the sensitivity to these changes of initial conditions and forcings. The best solution was then selected by means of a comparison of drift computations with all surface drift observations including the latest that had been collected from fishermen. Various combinations between sets of modelled currents and winds and between the modelled currents and the drift observations were evaluated. Probabilistic approaches were also tested such as ensembles of forward drifts minimising the distance to the various observations, and ensembles of backward drifts using the leeway version of the MOTHY model. All results were intercompared and common features were outlined.

\subsection{Observational dataset}

In this paragraph, we shortly recall what observational data were available to validate and to be combined with the modelled currents. The reader is invited to read the extensive report of the "drift committee" (Ollitrault et al. 2010) published by BEA for a detailed description of the observational dataset.

\subsubsection{ARGO floats and SVP floats}

The ARGO floats (Gould et al. 2004) currently sample the ocean from the surface to approximately $1,500 \mathrm{~m}$ (most frequent maximum immersion). They measure temperature and salinity profiles and lately a small part of these profilers started to deliver biogeochemical measurements such as oxygen. Every 10 days they surface for $12 \mathrm{~h}$ and transmit their measurements to a satellite. Temperature and salinity real-time observation profiles from ARGO floats are assimilated by most ocean forecasting systems in the world (including Mercator Océan). The trajectory of ARGO floats during their $12 \mathrm{~h}$ stay at the surface can be used to directly validate computed drift or to derive surface currents (Ollitrault et al. 2010).
The Global Drifter Program and Surface Velocity Program (SVP) drifting floats or "drifters" observations (Lumpkin and Pazos 2006) are obtained from the Atlantic Oceanographic and Meteorological Laboratory. These drifting floats are drogued with a holey sock (40 m deep) which allows them to sample the ocean currents at an averaged depth of $15 \mathrm{~m}$. Their trajectories can be compared directly to drift predictions or can be used to derive velocities every 6 h. Finally, daily filtered velocities are also used for validation.

The direct effect of the wind on both types of floats is supposed to be negligible. Grodsky et al. (2011) recently pointed out that SVP floats can sometimes provide surface measurements instead of $15-\mathrm{m}$ measurements when there is no warning about the loss of their drogues. In such case, windage can excess $1 \%$ of the $10-\mathrm{m}$ wind speed and has to be taken into account.

In this study, the SVP observations and ARGO surface drifts were used mainly for validation as no velocity information could be assimilated in the Mercator Océan systems at that moment. Nevertheless, it was possible to post-process the modelled velocity fields and to nudge them towards all available velocity observations, as explained in Section 2.3.

\subsubsection{Observations from search at sea}

Debris and human remains from the AF447 flight started to be sighted only 5 days after the accident. These observations (location and time of sighted and recovered debris from the airplane) came from many different sources and were assembled in a database at BEA who analysed the data and discarded the most doubtful information. The trajectory or position of the debris in the days that followed and before their full recovery was used to validate the drift computations from 5 th to 17 th June at the latest. They were used to build a score for forward modelled drifts as described in Section 2.3.

A subsample of observations was used as initial positions for backward drift computations, in order to estimate the likely position of the wreckage. The "drift committee" had to select debris or human remains that were the most representative, reliable, and well described. These observations also had to be the closest to the 1st of June. Table 1 lists the observations that were kept and illustrates the heterogeneity of these observations. The locations of these observations are also displayed in Fig. 1.

The immersion rate was kept constant during the backward drift computation for the debris (two immersion rates are generally tested, three for the debris sighted by the Singaporean ship Ursula). However, for the " $3 \mathrm{Z}$ body", the immersion rate shifts from $100 \%$ during the first day in the ocean (1st to 2 nd of June at 0200 hours) to $70 \%$ for all next days, according to the expertise of BEA. This rule 
Table 1 Debris and body recovered from the AF447 flight and that were used to initialise reverse drift computations with MOTHY

\begin{tabular}{|c|c|c|c|c|c|c|}
\hline \multirow[t]{2}{*}{ Name } & \multirow[t]{2}{*}{ BEA number } & \multicolumn{2}{|c|}{ Location of recovery } & \multirow[t]{2}{*}{ Date } & \multirow{2}{*}{$\begin{array}{l}\text { Immersion rate (estimated } \\
\text { from photographs) }\end{array}$} & \multirow[t]{2}{*}{ Height $(\mathrm{cm})$} \\
\hline & & Latitude & Longitude & & & \\
\hline Debris (sighted by ship Ursula) & - & 3.6333 & -30.4467 & 5 June 2009 at 1610 hours & $70-90 \%$ & 50 \\
\hline G2 (galley) & 753 & 3.4715 & -30.6562 & 6 June 2009 at 1500 hours & $40-50 \%$ & 100 \\
\hline VTP (vertical tail plane) & 170 & 3.6133 & -30.6183 & 7 June 2009 at 1338 hours & $90-100 \%$ & 100 \\
\hline $3 Z$ body & 61 & 3.8133 & -30.4833 & 7 June 2009 at 1725 hours & $\begin{array}{l}100 \% \text { during } 24 \mathrm{~h} \\
\text { and } 70 \% \text { after }\end{array}$ & 30 \\
\hline S6 (galley) & 109 & 3.8233 & -30.585 & 8 June 2009 at 0915 hours & $30-40 \%$ & 30 \\
\hline
\end{tabular}

can only be applied to undamaged bodies. The other undamaged bodies have not been retained for our study because they were recovered after the " $3 \mathrm{Z}$ body".

When recovering the floating remains of the flight after the accident, people on-board the Ventôse (French navy vessel) observed calm wind phases when the ship was slowly drifting within the debris field. In situ current velocity estimates were deduced from these drift records of the Ventôse and were used for "data fitting" (Section 2.3). Finally, the Service Hydrographique et Océanographique de la Marine (SHOM) issued a precise bathymetry field (Fig. 1) from the in situ measurements of the research ship "Pourquoi Pas?" (Institut Français de Recherche pour l'Exploitation de la Mer (IFREMER)/SHOM) during phases 1 and 2.

\subsubsection{Fishermen buoys}

Drift and current velocity observations measured by fishermen in the vicinity of the accident were made available by CLS during the preparation of phase 3 . These measurements were made with floating objects of various shapes, drogued in order to measure subsurface ocean currents near $15 \mathrm{~m}$. These measurements have to be taken with caution, as the effective immersion rates of the floats could not be guaranteed. Nevertheless, observations of the same type have been used in the past at CLS and Mercator Océan to validate models as a complement to SVP drifters, and no major inconsistencies could be identified between those datasets.

Among all available observations, two of these floats were the closest to the LKP in space and time: \#42 and \#246 (Fig. 1). Thus, these two floats significantly influenced the results of this study as they were treated exactly as the SVP and ARGO floats.

\subsubsection{SURCOUF surface currents}

The SURCOUF products are analysed surface currents maps derived from observations (no numerical model is used). They were used in the evaluation of the models (Section 2.2.1) and for the final probability mapping described in Section 2.3. As in Bonjean and Lagerloef (2002), the geostrophic part of the surface currents is deduced from Sea Level Anomaly (SLA) observations while the Ekman component is derived from the European Center for Medium Range Forecast (ECMWF) wind analyses. A mean dynamic topography (Rio et al. 2005 ) is used to derive dynamic topography from SLA observations. We also note that only two SLA tracks cover the region during the week of the accident (not shown).

\subsection{Numerical modelling systems}

\subsubsection{The ARPEGE reanalysis: atmospheric conditions}

ARPEGE is the operational global weather forecasting system of Météo-France (Auger et al. 2010). It is a stretched model, on a spectral grid and with a semi-implicit semiLagrangian temporal scheme. It uses a 4D-VAR algorithm for its data assimilation, every $6 \mathrm{~h}$. An updated version, that became operational in April 2010, was used as a basis for an atmospheric reanalysis during the May-June 2009 period, with higher resolution ( 70 vertical levels, $1 / 5^{\circ}$ horizontally on the zone of interest) and updates of the physical parameterisations (stratiform rain and turbulent scheme). The system was also tuned to improve the atmospheric analysis, by a better specification of observations errors, background errors specified according to the covariance errors of a variational assimilation ensemble (Berre et al. 2007), increasing the number of assimilated satellite radiances, and updating the fast radiative transfer model from RTTOV8 to RTTOV9 (Saunders et al. 2010). For the purpose of this reanalysis, the weight of scatterometer surface neutral wind observations (Seawinds on QuikScat, AMI on ERS-2, and ASCAT on MetOp-2 (Payan 2010)) was multiplied by 4 in the assimilation. For data from Seawinds scatterometer, sensitive to the rain, a change of quality control flag allowed for more data to be assimilated near the rainy patterns (Portabella and Stoffelen 2001; Payan 2008). Finally, hourly outputs were produced in order to provide high temporal resolution information, and higher-resolution surface forcings to be applied to ocean models. 


\subsubsection{The PSY2 reanalysis: ocean currents}

The Mercator Océan PSY2 configuration including the Mediterranean Sea, Tropical and North Atlantic in its operational version PSY2V3R1 (hereafter referred to as PSY2OPER) uses the version 1.09 of NEMO. The bathymetry is a combination of ETOPO2 and GEBCO8 (see Table 2). A total variation diminishing (TVD) advection scheme (Zalesak 1979) for the tracers and an energy and enstrophy conserving scheme for the advection of momentum are used. A free surface filtering out the high-frequency gravity waves is used. A 1.5 turbulent closure is applied for the vertical mixing (turbulent kinetic energy (TKE) scheme from Blanke and Delecluse 1993). An isopycnal laplacian operator is used for the lateral diffusion on the tracers and a horizontal bilaplacian operator is used for the lateral diffusion on momentum. The daily atmospheric conditions from ECMWF analyses are transformed into heat fluxes with the CLIO bulk formulae (Goosse et al. 2001). The momentum fluxes (wind stresses) diagnosed by ECMWF are used directly. Monthly climatological runoffs are prescribed and come from the Dai and Trenberth (2002) database. Main rivers are spread and coastal runoffs are applied along the coast. The north and south boundaries are buffer zones where temperature and salinity fields are damped towards the Levitus monthly climatology (Levitus et al. 1998). To constrain the Mediterranean water outflow in the Atlantic at the right depth (around 1,000 $\mathrm{m}$ depth), a restoring zone toward climatological temperature and salinity is prescribed in the Gulf of Cadiz.

The SAM2 Data Assimilation software (Tranchant et al. 2008; Cummings et al. 2009) is developed at Mercator
Océan and is based on the Singular Evolutive Extended Kalman Filter formulation of Pham et al. (1998). The three-dimensional (3D) multivariate background error covariance statistics vary at each analysis via the use of an ensemble of $\mathrm{O}(250)$ anomalies. These anomalies are computed from a long numerical experiment with respect to a running mean so that they can give an estimate of the 7-day scale error on the ocean state at a given period of the year for temperature $(T)$, salinity $(S)$, zonal velocity $(U)$, meridional velocity $(V)$, and sea surface height ( $\mathrm{SSH})$. The analysis is done at the observation location. The First Guess at Appropriate Time approximation is made which means that the model equivalent of the observation is taken at the correct time even if the analysis is delayed. Nearly all the global ocean surface can be analysed once a week given the quasihomogeneous satellite coverage (SLA+SST analysis). The multivariate and multi-data analysis is localised, which means that it is $3 \mathrm{D}$ inside a local "bubble" bounded by correlation radii and centred on the analysis point. In the Tropical oceans, this zone is several degrees. The errors of the different types of observations are combined with the model error covariances in order to obtain the correction or "increment" from the innovation (observation minus model misfits). The increment once projected back onto the model space gives an optimal ocean state: in between all available observations, and following the model dynamics. The increment is multivariate as it depends from covariations between the errors of state variables.

The along track altimeter SLA from the AVISO data centre, the RTG-SST from the National Center for Environmental Prediction (NCEP), together with the temperature and salinity in situ vertical profiles from the CORIOLIS

Table 2 Summary of the model configurations that were used in the PSY2 runs

\begin{tabular}{|c|c|c|c|}
\hline Configuration & PSY2-OPER & PSY2-REANA & PSY2-ZOOM \\
\hline Domain & Atlantic $20^{\circ} \mathrm{S}-70^{\circ} \mathrm{N}+$ Mediterranean Sea & As PSY2-OPER & $\begin{array}{l}\text { Western Tropical Atlantic } \\
36-24^{\circ} \mathrm{W} \text { and } 1^{\circ} \mathrm{S}-9^{\circ} \mathrm{N}\end{array}$ \\
\hline Bathymetry & $\begin{array}{l}\text { If depth is }>300 \mathrm{~m}, \text { ETOPO2 } \\
\text { (Amante and Eakins 2009) } \\
\text { If depth is }<200 \mathrm{~m}, \text { GEBCO } \\
\text { (Becker et al. 2009) } \\
\text { If } 200 \mathrm{~m}<\text { depth }<300 \mathrm{~m} \text {, linear } \\
\text { combination of ETOPO2 and } \\
\text { GEBCO } 8\end{array}$ & As PSY2-OPER & As PSY2-OPER \\
\hline Vertical coordinate system & $\begin{array}{l}z+\text { partial step }+ \text { fixed volumes } \\
\quad(\text { linear free surface })\end{array}$ & As PSY2-OPER & $\begin{array}{l}z+\text { partial step }+ \text { variable } \\
\text { volumes (nonlinear } \\
\text { free surface) }\end{array}$ \\
\hline Data assimilation scheme & Sequential (7-day window) & Sequential (5-day window) & None \\
\hline Assimilated data & $\begin{array}{l}T \text { and } S \text { profiles (real-time mode), } \\
\text { altimetry (real time), RTG-SST } \\
\text { from the National Center for } \\
\text { Environmental Prediction (NCEP) }\end{array}$ & $\begin{array}{l}\text { Additional } T \text { and } S \text { profiles (some } \\
\text { with delayed mode QC), altimetry } \\
\text { (delayed mode), RTG-SST from NCEP }\end{array}$ & None \\
\hline
\end{tabular}


data centre (IFREMER) are assimilated together. The Mean dynamic topography derived from observations from Rio et al. (2005) is used as a reference for SLA assimilation.

The reanalysis PSY2-REANA differs from the operational version PSY2-OPER mainly by the type of observations that were assimilated. SLAs were post-processed by AVISO (large-scale bias and orbit corrections), and temperature and salinity vertical profiles were quality controlled by CORIOLIS. The assimilation time window was shortened to 5 days in the PSY2-REANA experiment instead of 7 days in the real-time PSY2-OPER system. This allowed putting more weight on the observations at the analysis stage, especially the SST observations.

\subsubsection{A regional refinement of PSY2}

A zoom with no data assimilation was then nested into the PSY2-REANA experiment. The zoom domain chosen is $36-24^{\circ} \mathrm{W}$ and $1^{\circ} \mathrm{S}-9^{\circ} \mathrm{N}$. The bathymetry and the grid coordinates come from PSY2-OPER and were directly extracted from its configuration files. The model is initialised with a PSY2-REANA restart file and the lateral boundaries are forced by the outputs of PSY2-REANA at the daily frequency. The sequential data assimilation scheme induces jumps of the solution after the initialisation stage. Thus, PSY2-REANA outputs have been filtered (low pass) to ensure the continuity on the boundary forcing and to avoid the generation of spurious waves in the nested zoom domain. The variables considered are: $T, S, U, V$, and SSH.

Rather than performing a grid refinement (the resolution and bathymetry are the same as in PSY2-REANA, at $1 / 12^{\circ}$ ), we chose to improve the physics of the model to allow a better representation of small-scale processes. The model features used for the zoom experiments (called PSY2ZOOM) are compared with those of PSY2-OPER and PSY2-REANA in Tables 2, 3 and 4. The PSY2-ZOOM experiments include tides and benefit from improvements of the numerical schemes. For instance, a new version of TKE (here called TKE2) suppresses the numerical noise that had to be filtered out in PSY2-OPER and PSY2-REANA.
The update frequency of the atmospheric forcing is daily (daily averages) for the PSY2-OPER and PSY2-REANA systems, and 3-hourly in the PSY2-ZOOM experiments. In addition, the effect of the atmospheric pressure is taken into account in the bulk formulae of the forcing fields of the embedded zoom.

\subsubsection{The MOTHY drift computations}

The drift model MOTHY (Daniel et al. 2002) relies heavily in wind-parameterisation of the currents. The water velocity is provided by a coupling between a 2D hydrodynamic limited area ocean model and a 1D eddy viscosity model. MOTHY only uses external ocean model data from a single depth typically at the base of the Ekman layer - in the place of a climatological background current, and calculates the main drift component from the wind and tide data. It parameterises the upper ocean drift from wind speed using a sophisticated Ekman type scheme (Poon and Madsen 1991). On continental shelves, the $2 \mathrm{D}$ model provides a strong constraint to the $1 \mathrm{D}$ model by the interaction of currents due to tide, wind and topography. In contrast, above the ocean basins, the combination of currents from operational oceanography systems and wind (1D) drive the drift. This is the case in the region of interest of the western Equatorial Atlantic. Once the currents have been computed, they can be used to evaluate the drift of a body or an object at sea. MOTHY proposes two ways for that: a container model for semi-submerged objects and a leeway model.

In the first case, the main forces on any floating object container type are computed, depending on its immersion rate, and its trajectory is deduced.

In the second case, a Monte Carlo-based stochastic ensemble trajectory model calculates the motion of objects on the sea surface under the influence of wind and surface currents. The output is then an approximation of the time and space probability distribution converted in a spatial search area, in the form of an ensemble of particle positions. Drifting objects are divided into classes, e.g., a person in water (PIW), various classes of life rafts, small motor boats, etc. (Allen and Plourde 1999; Breivik and Allen 2008), each object having a particular set of parameters for leeway calculation.

Table 3 Summary of the forcing functions that were used in the PSY2 runs

\begin{tabular}{|c|c|c|c|}
\hline Forcing function & PSY2-OPER & PSY2-REANA & PSY2-ZOOM \\
\hline Atmospheric forcings & ECMWF daily for all fields & As PSY2-OPER & $\begin{array}{l}\text { ECMWF daily for all fields except wind stress }(3 \mathrm{~h}) \\
\text { For ZOOM2 only, ARPEGE reanalysis wind forcing }(1 \mathrm{~h})\end{array}$ \\
\hline Surface boundary condition & $\begin{array}{l}\text { CLIO with a constant value for the } \\
\text { atmospheric pressure }\end{array}$ & As PSY2-OPER & CLIO including atmospheric pressure effect \\
\hline ECMWF fields corrections & None & As PSY2-OPER & $\begin{array}{l}\text { Precipitation corrected with the Global Precipitation } \\
\text { Climatology Project (GPCP) data } \\
\text { Cloud cover corrected with the International Satellite } \\
\text { Cloud Climatology Project (ISCCP) data }\end{array}$ \\
\hline
\end{tabular}


Table 4 Summary of the parameterisations that were used in the PSY2 runs

\begin{tabular}{|c|c|c|c|}
\hline Parameterisations & PSY2-OPER & PSY2-REANA & PSY2-ZOOM \\
\hline Tides & None & As PSY2-OPER & $\begin{array}{l}7 \text { components (TPXO, Egbert and } \\
\text { Erofeeva 2002) }\end{array}$ \\
\hline Free surface resolution & Filtered with elliptic solver & As PSY2-OPER & $\begin{array}{l}\text { Time-splitting with tidal and } \\
\text { atmospheric pressure effects }\end{array}$ \\
\hline Turbulence & TKE & As PSY2-OPER & TKE2 (update) \\
\hline Advection scheme for tracers & $\begin{array}{l}\text { TVD advection } \\
\text { scheme (Zalesak 1979) }\end{array}$ & As PSY2-OPER & $\begin{array}{l}\text { QUICKEST (Leonard 1979) + } \\
\text { ULTIMATE (Leonard 1991) }\end{array}$ \\
\hline Lateral tracer diffusion & $\begin{array}{l}\text { Laplacian along the isopycnal slopes } \\
\left(125 \mathrm{~m}^{2} \mathrm{~s}^{-1}\right)\end{array}$ & As PSY2-OPER & $\begin{array}{l}\text { None (implicit diffusion in the } \\
\text { advection scheme) }\end{array}$ \\
\hline Advection scheme for momentum & $\begin{array}{l}\text { Vector form, energy and enstrophy } \\
\text { conserving scheme }\end{array}$ & As PSY2-OPER & As PSY2-OPER \\
\hline Lateral viscosity & $\begin{array}{l}\text { Bilaplacian operator along the geopential } \\
\left(-1.25 \mathrm{e}^{2} 0 \mathrm{~m}^{2} \mathrm{~s}^{-1}\right)\end{array}$ & As PSY2-OPER & As PSY2-OPER \\
\hline Bottom friction & Nonlinear $(1 \mathrm{e}-3)$ & As PSY2-OPER & As PSY2-OPER \\
\hline Density & UNESCO (Jackett and McDougall 1995) & As PSY2-OPER & As PSY2-OPER \\
\hline Solar penetration & Water type I & As PSY2-OPER & As PSY2-OPER \\
\hline
\end{tabular}

In this study, the currents are used in two ways by MOTHY: the currents are prescribed either at the surface (and MOTHY just adds the wind drag on the emerged part of the objects) or just below the Ekman layer (at an around $30 \mathrm{~m}$ depth). In the second case, MOTHY computes the ocean currents in the Ekman layer and the effect of the wind on the object drift.

\subsection{Numerical experiments}

\subsubsection{Ocean and wind}

Table 5 gives an overview of all the numerical experiments that were performed including the ARPEGE reanalysis, the PSY2 reanalysis (PSY2-REANA) and the PSY2-ZOOM experiments.

Two different types of zoom experiments have been performed varying only the origin and frequency of the wind stress forcing. In the PSY2-ZOOM1 category 3-h wind stresses from ECMWF were used, and in the PSY2-ZOOM2 category (only one experiment) 1-h wind stresses were used, taken from the ARPEGE reanalysis. Finally, as summarised in Table 5, five different experiments were available to assess the impact of initial condition errors and the impact of atmospheric forcing field errors: in the case of PSY2-ZOOM1 four numerical experiments were started from different dates in order to vary the initial condition; and a comparison between PSY2-ZOOM2 and PSY2-ZOOM1 experiments gives an estimate of the sensitivity to surface wind errors. All the PSY2-ZOOM experiments have daily averaged 3D output files and instantaneous hourly surface outputs.

\subsubsection{Drift experiments}

With all this variety of input data, the MOTHY system was run to perform drift computations following twenty-one different configurations. Twenty out of twenty-one were build from the two wind analyses (ECMWF and ARPEGE); the five types of ocean current analyses or model outputs (PSY2-REANA, one of the four PSY2-ZOOM1, PSY2ZOOM2, SURCOUF surface currents deduced from observations, and the PSY2-OPER ocean currents); and the two different current depths (current was prescribed either at the
Table 5 Summary of the characteristics of the different numerical experiments

\begin{tabular}{llll}
\hline Name of experiment & Wind stress forcing (for ocean models) & Start & End \\
\hline ARPEGE & & 25 May 2009 & 15 June 2009 \\
PSY2-REANA & ECMWF (1 day) & 5 May 2009 & 1 July 2009 \\
PSY2-ZOOM1 & ECMWF (3 h) & 26 May 2009 & 15 June 2009 \\
& ECMWF (3 h) & 11 May 2009 & 12 June 2009 \\
& ECMWF (3 h) & 16 May 2009 & 12 June 2009 \\
& ECMWF (3 h) & 21 May 2009 & 12 June 2009 \\
PSY2-ZOOM2 & ARPEGE (1 h) 2009 & 15 June 2009 \\
21 MOTHY configurations & Reproducing 8 observed drifts on the May-June period (see text and Table 6)
\end{tabular}


surface or below the Ekman layer). Finally the highfrequency PSY2-ZOOM2 oceanic outputs (hourly instead of daily) were tested into one more drift experiment using ARPEGE winds. The MOTHY experiments that were performed are all listed in Table 6. For each of the twenty-one configurations, drifts forecasts were performed with both a $90 \%$ and a $100 \%$ immersion rate.

\section{Evaluation of the error on the location of the wreck}

Due to the level of uncertainty of ocean currents, the unknowns on the winds and degree of immersion of the objects and the very few observations at hand it was challenging to establish objective or (even statistical) criteria to compare and rank the results of different model experiments. It was even more difficult to produce error bars for the drift computations. For all available surface current fields produced by the group during phase 3, a systematic visual inspection of the flow (and comparison with observations) was first performed. This inspection revealed the consistency of all results at large scale, and less agreement on the smaller scales, which is reflected by the ocean drift computations as displayed in the main report of the group of Ollitrault et al. (2010). In this article we describe two different contributions to the estimation of the errors of surface currents and drift computations. These methods make use of the fact that an ensemble of modelled currents and drifts was produced. As the problem is under-observed and large uncertainties take place, the ensemble methods offer a way to estimate a level of confidence or degree of uncertainty.

We first illustrate the spatial variations of the model errors using the model currents only (from PSY2-ZOOM ensemble) and without computing trajectories.

The Eulerian time RMS error of the $\mathrm{U}$ and $\mathrm{V}$ surface currents due to two major sources of error in the ocean model outputs can be computed from the PSY2-ZOOM ensemble. These sources are the atmospheric forcing at the surface (difference between PSY2-ZOOM1 and 2), and the oceanic initial conditions (series of PSY2-ZOOM1 experiments).

The hourly currents of the five different experiments were averaged together to form an ensemble mean. Squared deviations from this mean were then averaged over time and over the ensemble in order to obtain the ensemble spread in $\mathrm{U}$ and $\mathrm{V}(\mathrm{m} / \mathrm{s})$. The spread in $\mathrm{m} / \mathrm{s}$ was then converted into a distance in $\mathrm{km}$ after 5 days. This method gives a rough evaluation of the likely maximum error due to the local variability of the solution associated with the principal sources of uncertainty. As can be seen in Fig. 3, inside the $74 \mathrm{~km}$ circle and in the vicinity of this circle the error
Table 6 Score (sum of the model errors for the eight validation cases) obtained by MOTHY for the 21 numerical drift experiments performed using all possible combinations of available environmental input (see text)

The right column indicates the rank for the ten smallest cumulated errors

$E k$ the current is prescribed just below the Ekman layer, Surf the current is prescribed at the surface

aThe 7 "better" couples

\begin{tabular}{|c|c|c|c|c|}
\hline Ocean model & $\begin{array}{l}\text { Under Ekman layer (Ek) } \\
\text { or surface current (surf) }\end{array}$ & Atmospheric model & $\begin{array}{l}\text { Sum of the } 8 \\
\text { model errors }\end{array}$ & $\begin{array}{l}\text { Rank of the } \\
10 \text { first }\end{array}$ \\
\hline PSY2-OPER & $\mathrm{Ek}$ & ECMWF & 440 & \\
\hline PSY2-OPER & Ek & ARPEGE & 468 & \\
\hline PSY2-OPER & Surf & ECMWF & 394 & 10 \\
\hline PSY2-OPER $^{\mathrm{a}}$ & Surf $^{\mathrm{a}}$ & ARPEGE $^{\mathrm{a}}$ & $374^{\mathrm{a}}$ & $7^{\mathrm{a}}$ \\
\hline PSY2-REANA & Ek & ECMWF & 769 & \\
\hline PSY2-REANA & Ek & ARPEGE & 769 & \\
\hline PSY2-REANA ${ }^{\mathrm{a}}$ & Surf $^{\mathrm{a}}$ & ECMWF $^{\mathrm{a}}$ & $365^{\mathrm{a}}$ & $5^{\mathrm{a}}$ \\
\hline PSY2-REANA ${ }^{\mathrm{a}}$ & Surf $^{\mathrm{a}}$ & ARPEGE $^{\mathrm{a}}$ & $345^{\mathrm{a}}$ & $4^{\mathrm{a}}$ \\
\hline PSY2-ZOOM1 & Ek & ECMWF & 821 & \\
\hline PSY2-ZOOM1 & Ek & ARPEGE & 877 & \\
\hline PSY2-ZOOM1 & Surf & ECMWF & 684 & \\
\hline PSY2-ZOOM1 & Surf & ARPEGE & 667 & \\
\hline PSY2-ZOOM2 & Ek & ECMWF & 664 & \\
\hline PSY2-ZOOM2 & Ek & ARPEGE & 668 & \\
\hline PSY2-ZOOM2 $^{\mathrm{a}}$ & $\operatorname{Surf}^{\mathrm{a}}$ & ECMWF $^{\mathrm{a}}$ & $241^{\mathrm{a}}$ & $2^{\mathrm{a}}$ \\
\hline PSY2-ZOOM2 ${ }^{\mathrm{a}}$ & Surf $^{\mathrm{a}}$ & ARPEGE $^{\mathrm{a}}$ & $229^{\mathrm{a}}$ & $1^{\mathrm{a}}$ \\
\hline PSY2-ZOOM2 HF & $\operatorname{Surf}^{\mathrm{a}}$ & ARPEGE $^{\mathrm{a}}$ & $275^{\mathrm{a}}$ & $3^{\mathrm{a}}$ \\
\hline SURCOUF & Ek & ECMWF & 383 & 8 \\
\hline SURCOUF & Ek & ARPEGE & 383 & 9 \\
\hline SURCOUF $^{\mathrm{a}}$ & $\operatorname{Surf}^{\mathrm{a}}$ & $\mathrm{ECMWF}^{\mathrm{a}}$ & $373^{\mathrm{a}}$ & $6^{\mathrm{a}}$ \\
\hline SURCOUF & Surf & ARPEGE & 439 & \\
\hline
\end{tabular}


Fig. 3 Five-day travel error (in kilometers) estimated from the ensemble spread of PSY2ZOOM surface currents (see text). The LKP position is indicated with a black triangle and the $74-\mathrm{km}(40 \mathrm{~nm})$ circle with a thick black line. Ellipses (thin black lines) illustrate the local anisotropy of the model spread: one axis is the zonal and the other is the meridional distance. For more visibility, one ellipse out of six in the zonal direction and one out of eight in the meridional direction are kept

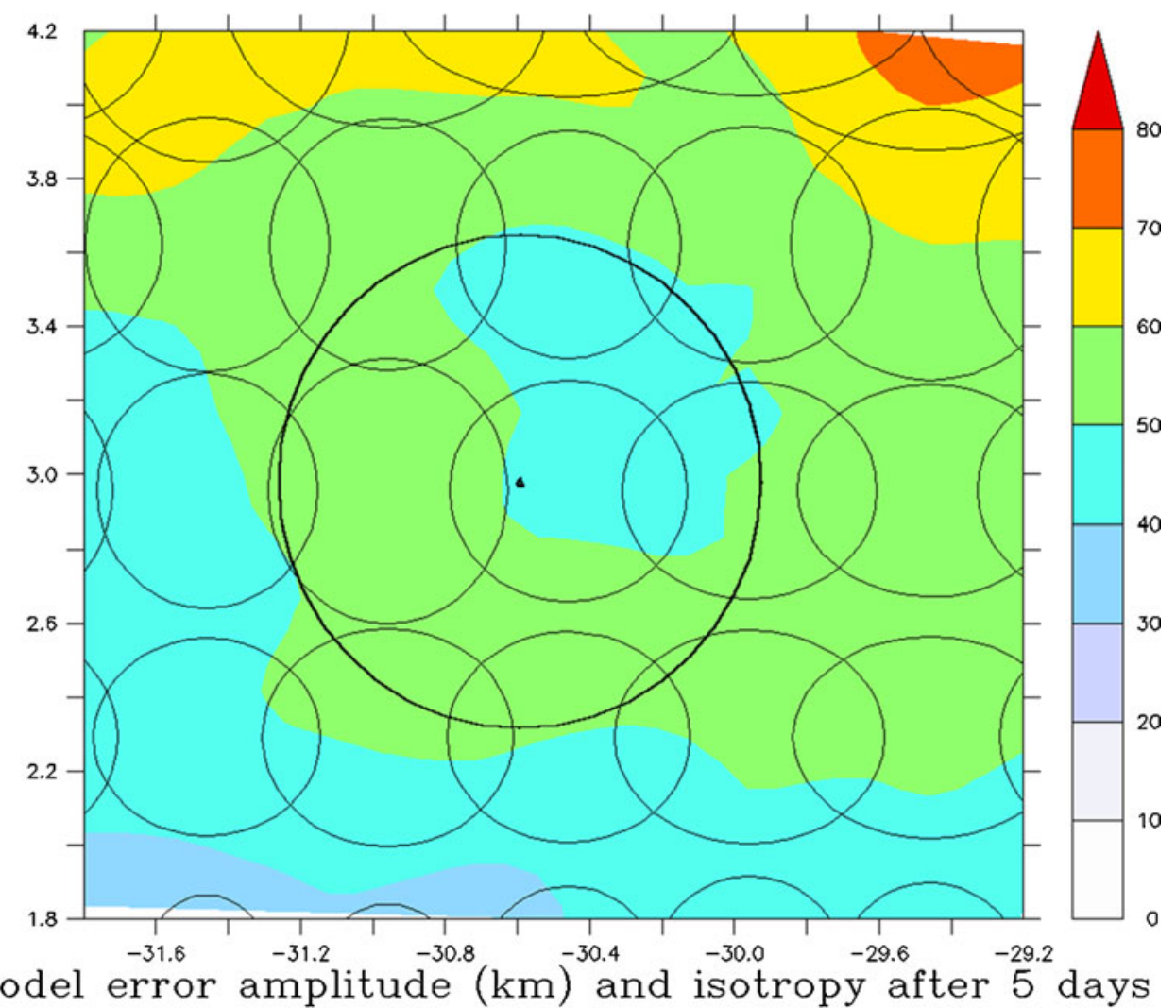

estimation obtained was of the order of $40 \mathrm{~km}$ to $50 \mathrm{~km}$. The error is quasi-isotropic inside the $74 \mathrm{~km}$ circle.

With new observations from fishermen delivered at the end of the year 2009, it was possible to evaluate the models with respect to observations sufficiently close to the accident in space and time. Two fishermen buoys appeared to be the most relevant observations for the validation of drift calculations: \#246 and \#42. They were close to the LKP and drifted during the whole time period that was most pertinent to compute the backward drift (from 1st to 8th June).

The ensemble of drift experiments performed with MOTHY was compared with drift observations as illustrated in Fig. 4. Positioning errors at the end of the drift were computed to help validate the modelled currents and select the best configuration for MOTHY drift computations in the region and period of interest. We chose six drift periods to assess the quality of the modelled drifts: 7.5 (between $31 \mathrm{st}$ May at 1800 hours and 8th June at 0600 hours), 5.5 (from 2nd June at 1800 hours to 8th June at $0600 \mathrm{~h}$ ), and 3.5 days (from 4th June at 1800 hours to 8th June at 0600 hours) for the buoy \#246; 6.5 (from 1st June at 1800 hours to 8th June at 0600 hours), 4.5 (from 3rd June at 1800 hours to 8th June at 0600 hours), and 2.5 days (from 5th June at 1800 hours to 8th June at 0600 hours) for the buoy \#42. Besides, two Argo buoys have been retained for the validation: the \#692 $\left(3900692 ; 3.62^{\circ} \mathrm{N}, 29.04^{\circ} \mathrm{W}\right)$ with a drift on 1 st June from 1210 to 2300 hours and the \#78 (1901078; $\left.4.24^{\circ} \mathrm{N}, 32^{\circ} \mathrm{W}\right)$ with a drift from 5th June at 1512 hours to 6th June at 0200 hours. These two Argo drifts lasted only $11 \mathrm{~h}$, but their spatial position was different from the fishermen buoys drifts and not too far in space and time from the LKP.

The modelled drift positioning errors were computed for each of the 21 drift configurations, for both the 90 and $100 \%$ immersion rates. The errors were then cumulated on the eight validation cases for each type of immersion rate, and the average result is finally displayed in Table 6. As the Argo drifts are of relative short duration, they were less pertinent than the fishermen buoys and their contribution to the score was not significant. With or without Argo drifts, the cumulated scores indicate that drifts produced using PSY2-ZOOM2 ocean currents are the most realistic (in terms of final position). An alternate score can be computed by weighting the positioning error by the total drifted distance for each individual drift. This score is presented in Fig. 5 for drifts issued from buoys \#246 and \#42 only, and for drifts computed with ARPEGE winds. Again PSY2ZOOM2 obtains the best scores, and is even better than the SURCOUF product which is based only on observations. PSY2-REANA and PSY2-ZOOM1 do not perform significantly better than PSY2-OPER, suggesting that the ARPEGE wind forcing (of higher quality and frequency) is improving the results. A large dispersion appears between the various drift estimates, as also illustrated in Fig. 4. We note that all drifts reproduce a north-eastward movement. In 
Fig. 4 Forward drifts with MOTHY initialised at the position of the fishermen buoy \#246 on 2009 June 6th at 1800 hours UTC. The buoy drift for the following 5.5 days is indicated with the red dashed line. The ocean currents (here, surface currents) and wind forcings are varied to perform the various drift computations (cyan, ARPEGE with PSY2OPER; yellow, ECMWF with PSY2-REANA; purple, ARPEGE with PSY2-REANA; blue, ECMWF with SURCOUF; brown, ECMWF with PSY2-ZOOM2; green,

ARPEGE with PSY2-ZOOM2 high-frequency outputs; and black, ARPEGE with PSY2ZOOM2 daily outputs). Two different immersions were tested-90\% (indicated with a 9 ) and $100 \%$ (indicated with a 0 ). The map shows the LKP of the plane (ACARS point represented by a blue triangle)

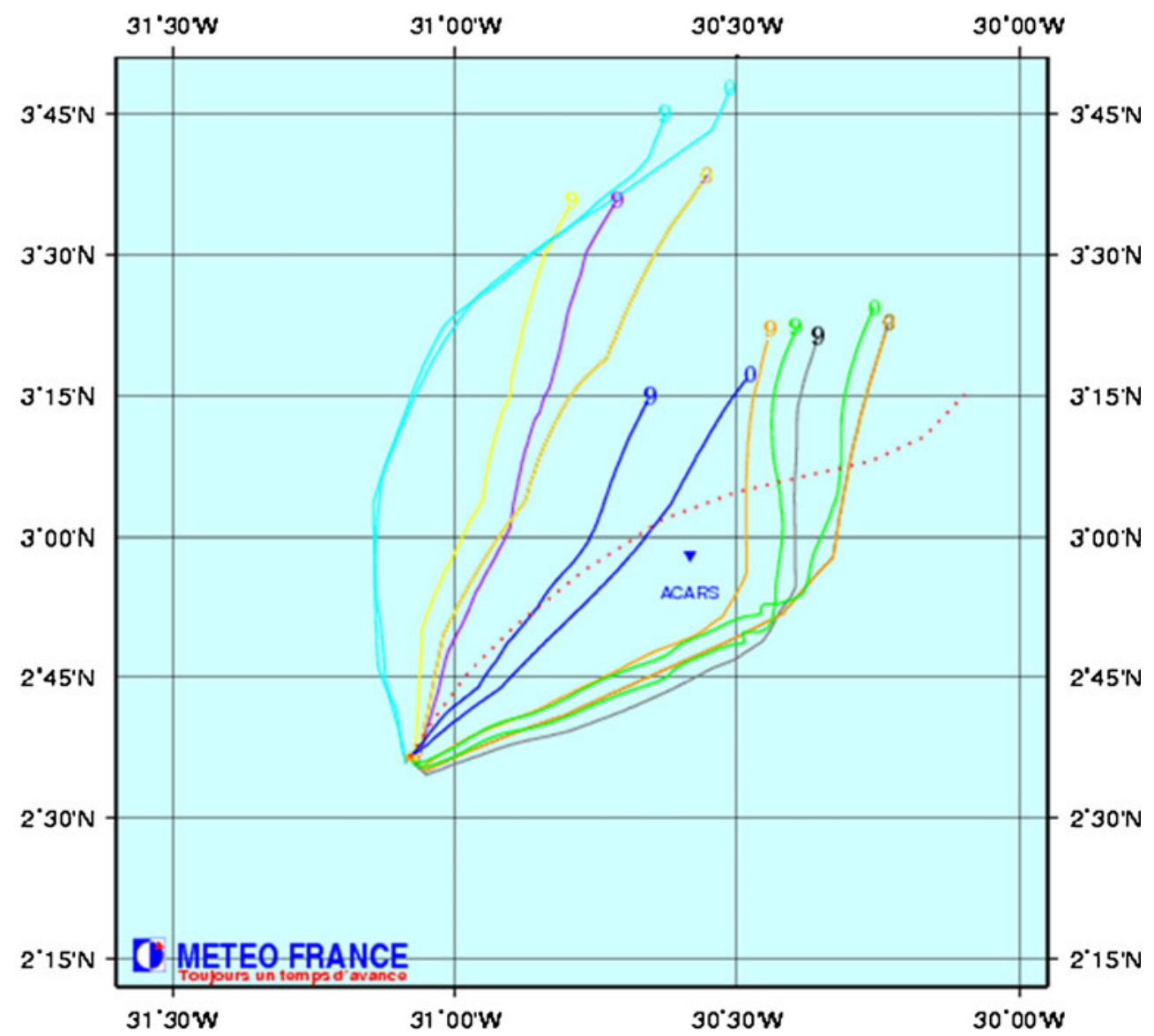

most cases, the $100 \%$ immersion seems to improve the trajectories for the buoy \# 246. The cumulated scores of Table 6 are of the same order of magnitude for ARPEGE and ECMWF winds, and the histogram of weighted scores computed with the drifts performed with ECMWF winds is not significantly different from Fig. 5 (not shown). These results show the interest of ARPEGE winds as a wind forcing for the PSY2-ZOOM2 ocean model, but the use of ARPEGE winds instead of ECMWF to compute the effect of the wind on the drifting object does not make a significant difference. This suggests that the direct effect of the wind on the fishermen buoys drift is negligible (100\% immersion).

\section{Model and observations post-processing and combination: an ensemble approach to define a search zone}

\subsection{Improving modelled currents with observed velocities}

It was chosen here to refine the currents in a post-processing stage, as no proper data assimilation of surface drifters could be implemented in PSY2-REANA to be ready for phase 3. A Successive Correction Method with a Gaussian filter was used to model the covariances in time and in the zonal and meridional directions. The recursive filter is described in Hayden and Purser (1995). It was especially designed to provide a computationally efficient interpolation method capable of producing realistic results for datasets with spatial heterogeneities of coverage. Its basic computational steps for a single pass of the analysis may be summarised as follows: first guess (or background) values are interpolated onto observation locations (a nearest neighbour interpolation was performed), then the observation increments (observed value minus interpolated background) are spread to the neighbouring grid points, and the resulting field of increments is then smoothed through repeated application of a digital Gaussian filter.

The passes are applied as successive corrections of the previous estimate. Ten analysis passes were performed. Here, the same 3D anisotropic Gaussian filter is used for all the iterations. In this study, the spatial covariances are represented by a Gaussian kernel of zonal scale $\mathrm{rcx}=0.8^{\circ}$ and meridional scale rcy $=0.4^{\circ}$. The time dependency is taken into account with a Gaussian scale of $\mathrm{rct}=3$ days.

This fit towards the velocity observations (hereafter referred to as "data fitting") was used to build composites between the model currents and the observations. In other words, this method offered the possibility of nudging the model currents 


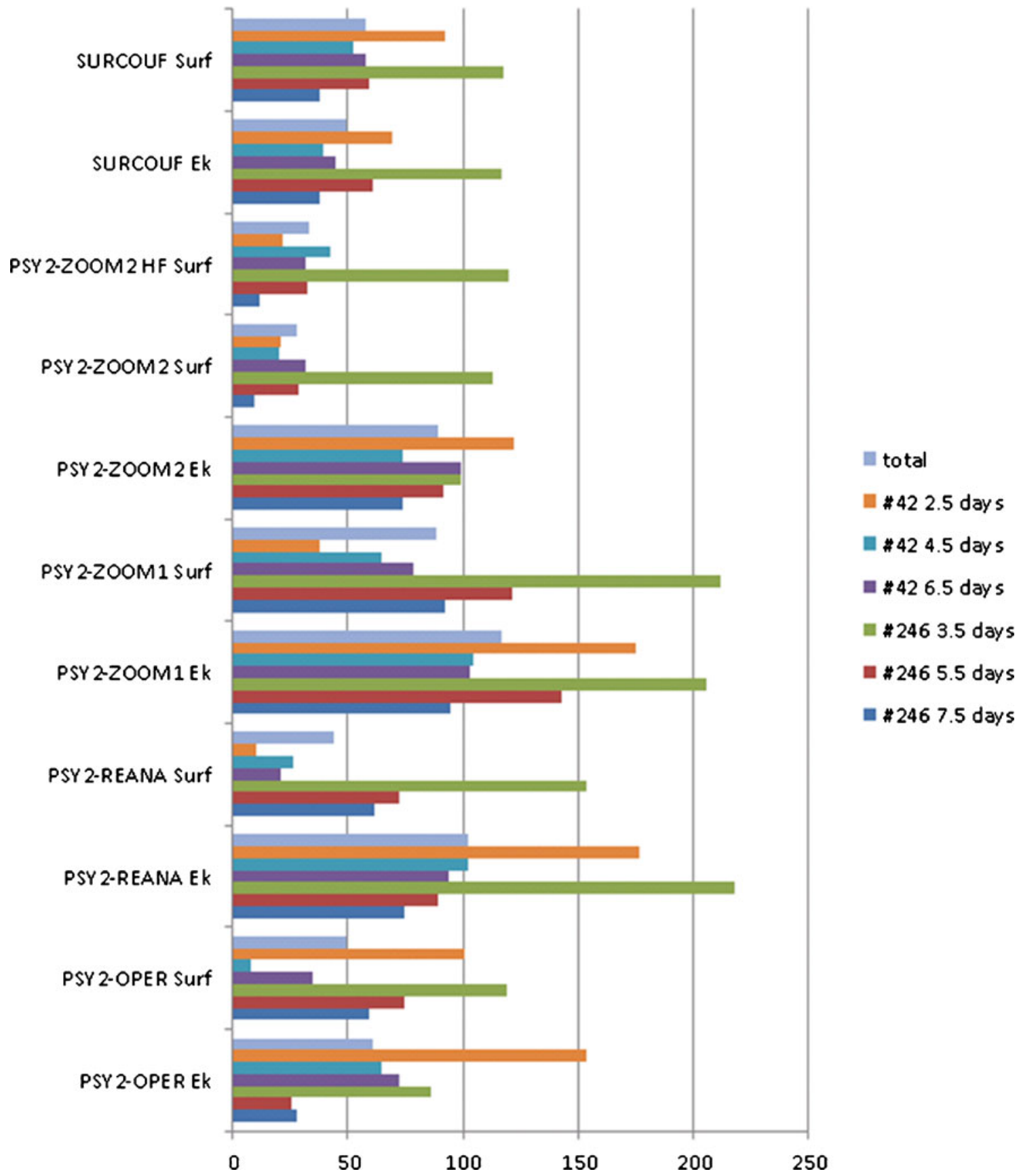

Fig. 5 Modelled drift position error relative to the overall drifted distance (in percent) for six observed drifts of different duration, drifts use ARPEGE winds. Currents are prescribed at the surface (Surf) sampled from the fishermen buoys \#246 and \#42. All these MOTHY or just below the Ekman layer $(E k)$

towards the drift observations. As described in the following sub-section, it was also useful to estimate the impact of the uncertainties on surface currents in the drift computations.

\subsection{Composite from the PSY2 ensemble experiments}

The results of Scott et al. (2012) suggest that a linear combination of different numerical experiments could have a better skill than any individual experiment taken separately. The day-by-day average between PSY2-REANA, PSY2ZOOM1, and PSY2-ZOOM2 was thus computed (hereafter referred to as PSY2-AVG) but unfortunately did not display a better skill than PSY2-ZOOM2 with respect to the observations that were available (see Section 2.2.1). Nevertheless, this computation was used to estimate the RMS error with respect to the fishermen buoys using the data fitting technique. 
The data fitting technique was applied to PSY2-AVG currents. The RMS difference between the $U$ and $V$ currents with and without data fitting then gives a mapping of the error estimate with respect to near surface current observations in metres per second. The error was then converted into a distance (in kilometres) after 5 days. As can be seen in Fig. 6, the error estimate after 5 days varies between 20 and $70 \mathrm{~km}$ inside and in the vicinity of the $74-\mathrm{km}$ circle. The order of magnitude is the same in both directions. These error estimates are slightly larger than those based on the ensemble spread in Fig. 3. One must note first that it is an approximation to compare the near-surface (unknown depth) current velocities derived from the fishermen buoys positions to Eulerian ocean surface currents. Secondly, the error is by construction locally larger where data are available (and thus where the fitting changes the initial field). For instance near $4^{\circ} \mathrm{N}$, the error is large (up to 90-95 km) in the zonal direction. This can be attributed to the strong westward zonal flow indicated by the drifters at this latitude. Southwest of the 74-km circle, a strong error (up to $95 \mathrm{~km}$ ) appears in the meridional direction. This corresponds to the strong north-eastward current branch indicated by two of the fishermen drifters.
4.3 Monte Carlo backward drifts with the MOTHY leeway model

The leeway version of MOTHY can be used in this study only for the floating bodies because the behaviour of the debris in water is not known nor parameterised in the model. Thus backward drifts were initiated from the position of the $3 Z$ body and computed until 2009 June, first at 0000 hours. Four different combinations of input data were formed out of PSY2-ZOOM2 and PSY2-REANA currents, and ARPEGE reanalysis and ECMWF $10 \mathrm{~m}$ winds. These currents and winds were pointed out as the most accurate at the validation stage. PSY2-AVG was also used as input surface current, with and without data fitting (not shown).

As can be seen in Fig. 7, Monte Carlo backward drifts with PSY2-ZOOM2 and ARPEGE wind indicate the north of the $74 \mathrm{~km}$ circle whereas the drifts with PSY2-REANA and ARPEGE winds indicate a large north-north-west part of the $74 \mathrm{~km}$ circle as the most likely zone for the initial position of the wreckage. When ECMWF winds are used instead of ARPEGE winds (not shown), the same type of spatial patterns are obtained, with a slightly larger spread of the trajectories towards the south (in this case, the largest zone obtained with PSY2-REANA includes the LKP).
Fig. 6 Five-day travel differences (in kilometers) estimated from time RMS differences in each spatial point between the data-fitted PSY2AVG current and the original PSY2-AVG current. The LKP position is indicated with a black triangle and the 74-km circle with a thick black line. Ellipses (thin black lines) illustrate the local anisotropy of the difference. For more visibility, one ellipse out of six in the zonal direction and one out of eight in the meridional direction are kept

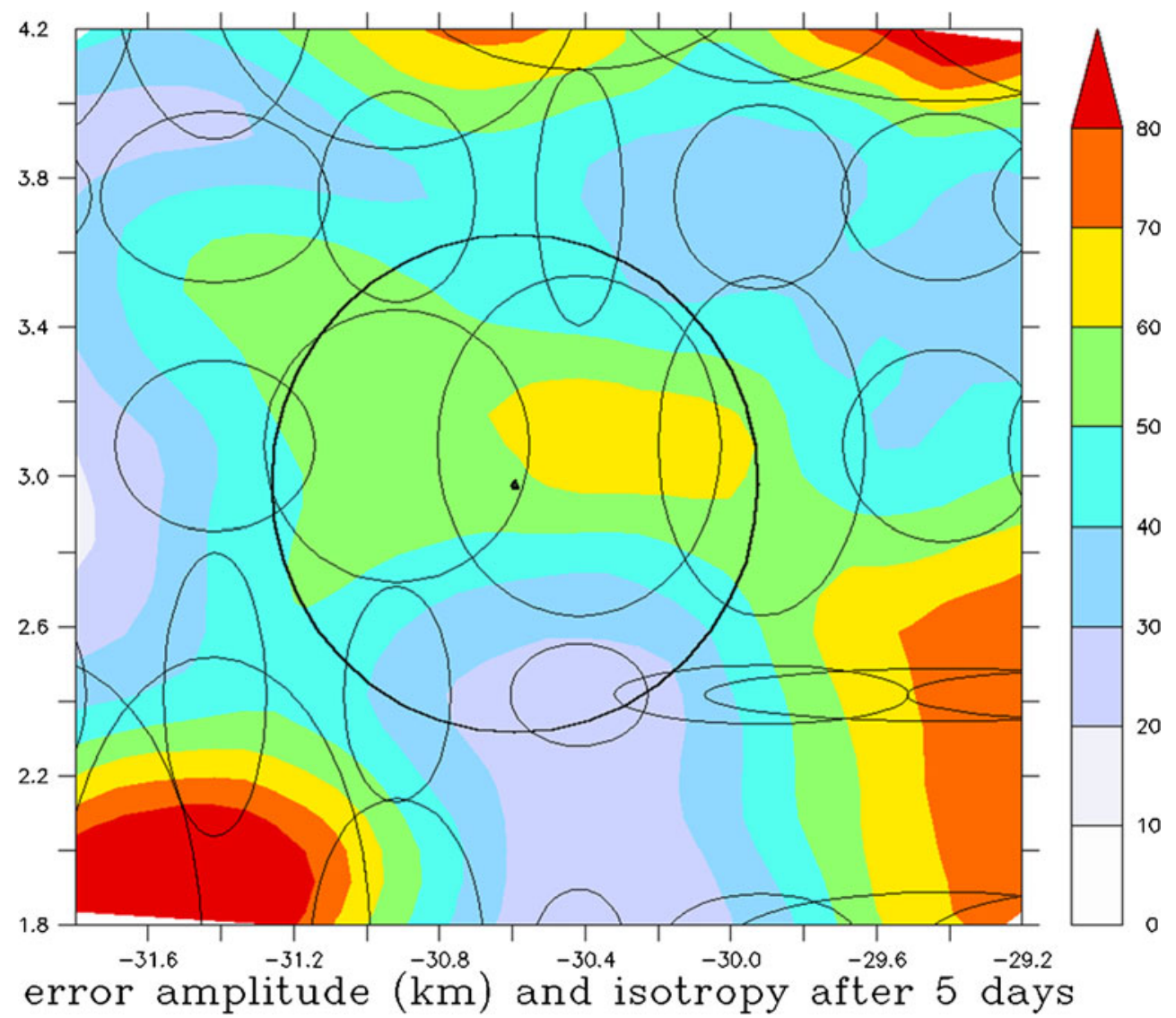


a)

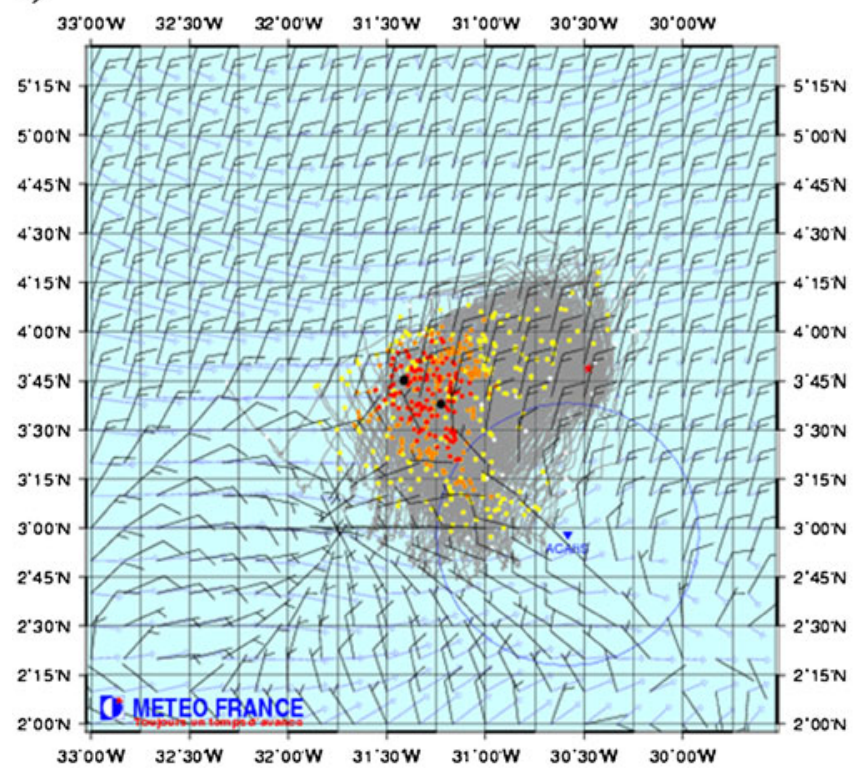

Fig. 7 MOTHY backward drift computation with leeway model, with PSY2-REANA surface currents and ARPEGE wind forcing (a) and with PSY2-ZOOM2 surface currents and ARPEGE wind forcings (b). The initial position was on 7th June 2009 at 1725 hours UTC, latitude $3^{\circ} 48.48^{\prime}$ North and longitude $30^{\circ} 28.60^{\prime}$ West which corresponds to the observed position of the $3 \mathrm{Z}$ body. The final date of integration was $1 \mathrm{st}$ June 2009 at 0000 hours UTC. The deterministic forecast is indicated with black dots (only the orientation of the object is varied). Coloured dots are probabilistic forecasts, obtained by considering the uncertainty on wind and currents and on the object's characteristics. By construction, the coloured dots define zones of increasing size and of increasing b)

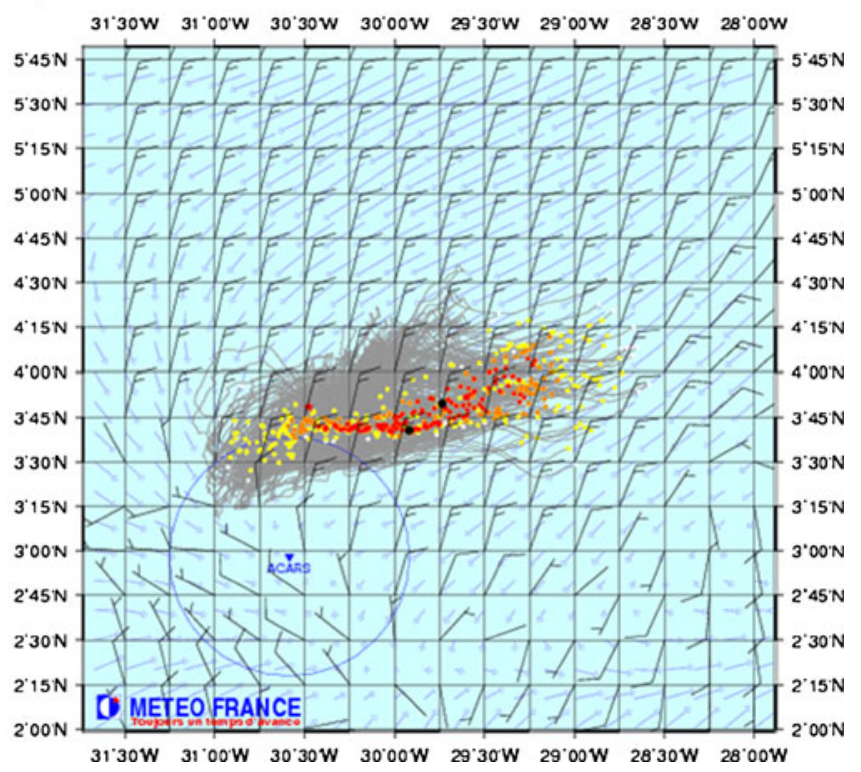

probability of presence for the wreckage. Colours correspond to the level of confidence assigned to the zones. The area bounded by the white dots has a confidence level of $99 \%$ (probability of finding the wreck estimated at $99 \%$ in the largest area); the area outlined in yellow has a confidence level of $95 \%$; the orange zone has a confidence level of $68 \%$; and finally, the smallest area in red has a confidence level of $50 \%$. The trajectories are in grey; the winds (black arrows with barbs) and the surface currents (grey arrows whose length is proportional to the module) on 1st June 2009 at 0000 hours UTC are displayed. The map shows the LKP (ACARS point represented by a blue triangle) and a blue circle centred on the ACARS point, with a $74-\mathrm{km}$ radius
The deterministic positions (mean positions of each leeway simulation indicated by a plain black circle in Fig. 7) are consistent with the positions obtained with the object version of MOTHY. The large spread of the results illustrates all the uncertainty in a body drift when it lasts several days. Moreover the backward trajectories are initiated near $4^{\circ} \mathrm{N}$ where large errors were diagnosed in the ocean current fields.

\subsection{Monte Carlo forward drifts varying all sources of errors}

The main idea was to use all the positions of recovered drifting material (debris and human remains) with unknown drifting characteristics as a test bed. More precisely, we searched, among all the possible current speeds and the various immersions, which trajectories were the closest to the observed positions of the drifting material.

In a 100-km circle around the LKP point, a large number of particles (or trajectories) are initialised at each grid point of a regular $1 / 12^{\circ}$ horizontal grid. The initial date of all particles was 1 st June at 0215 hours. In order to take into account all sources of uncertainties, a large number of trajectories start from one given point: with different wind drag (immersion) from 0 to $10 \%$ (from 100 to $90 \%$ immersion rates), with the model surface currents scaled by a factor of 0.7 to 1.4 , and with or without "data fitting" on the fishermen buoys (and Ventôse) drift observations. Particles were then advected under the combination of current and wind. The time counter was incremented during the integration (Runge-Kutta). When the trajectory encountered a recorded position for drifting material, a distance between the trajectory and the observation position was estimated. Note that this estimate was not unique.

If the trajectory arrived in the vicinity of the observation on the day of the observation, the orthodromic distance was computed. If there was a time lag larger than 1 day between the trajectory and the observation, then this time lag was converted into a distance via a given speed $(30 \mathrm{~cm} / \mathrm{s}$, the average speed of the debris and human remains over the 7 11 June period). Among the distances between all the trajectories initiated in one point and the observations, only one third of the smallest distances were kept. This aimed at reducing the impact of wrong observations (position or time). The average over the smallest values was computed and weighted by the number of observations for each date, thus giving less 
confidence to outliers. In the end, the score (hereafter referred to as the DIST score) is assigned to the initial point of the trajectory inside the $100-\mathrm{km}$ circle. DIST scores were computed for short duration drifts (from 1st to 7th June) and for longer duration drifts (from 1st to 17th June).

As illustrated in Fig. 8, the PSY2-REANA currents significantly improve the DIST score inside the $100-\mathrm{km}$ circle around the LKP with respect to PSY2-OPER. PSY2ZOOM2 currents slightly shift the highest DIST scores southward. Constraining the currents with the drift observations from fishermen buoys also significantly change the results: the zone with the highest DIST scores (in red) is a narrow band in this case. The best trajectories tend to follow the main north-eastward flow indicated by the observations. One can note that the multiple forward trajectories indicate quite different zones than the multiple backward trajectories of Fig. 7. In the forward case, the zone with the highest DIST score computed with PSY2-ZOOM2 (Fig. 8e, f) includes the region of the LKP, where the wreckage was finally found. The highest DIST scores obtained for longer duration forward drifts consistently point out the northern half of the circle as the most probable location of the wreckage (not shown).

A final composite score is displayed in Fig. 9 and represents more than 1,500,000 particles (a thousand particles in the $100-\mathrm{km}$ circle, 11 different drags or windages, 7 different multiplicative factors, and 5 different systems, only with data fitting).

This score is consistent with the deterministic estimates for the position of the wreckage, which cluster in the North and North West of the 74-km circle. These deterministic positions include those computed with modeled ocean currents from Finite-Volume Coastal Ocean Model (FVCOM; Chen et al. 2009). As described in Chen et al. (2012), this model was also used by the drift committee and was forced with winds from Weather Research and Forecasting model. This illustrates the overall consistency of the drift committee results, pointing out the North-North-western half of the 74-km circle as a probable area for the location of the wreckage.

We can note that this study has shown that most of the trajectories initiating from the North-western part of the circle were rejecting the effect of the wind on the debris; the best scores (of the order of $20 \mathrm{~km}$ ) were obtained with trajectories or particles with no windage effect. From this score, taking into account most uncertainties, we could anticipate that the crash could have taken place inside the $40-\mathrm{km}$ distance isoline, North-west of the LKP and more probably further than $37 \mathrm{~km}$ from the LKP.

\section{Discussion and conclusions}

The PSY2-ZOOM2 experiment forced with ARPEGE gives the best performance among the PSY2 experiments in terms
Fig. 8 In an 80-km circle centered on the LKP, the colour scale stands for the DIST score in kilometers for 7-day drifts (see text). The debris observations are indicated with black diamonds. A few forward drifts with highest DIST score are drawn with grey lines; the best DIST score drift is drawn with a thick black line (the associated DIST score is indicated in the lower right corner). A black dot labeled "PolSar" indicates the location of a pollution sighted by satellite SAR observations in the vicinity of the accident. In the upper panel, the drifts use surface currents from PSY2-OPER (a, b); in the middle panel, currents come from PSY2-REANA (c, d); and in the lower panel, they come from PSY2-ZOOM2 (e, f). Data fitting is applied on currents in the left column (a, c, e) while it is not applied in the right column (b, d, f)

of reproducing the fishermen buoys trajectories with MOTHY. Having checked the consistency between the different error estimates and comparison with observations, we can assume that the order of magnitude of the positioning error with PSY2-ZOOM is $50 \mathrm{~km}$ for the period and in the region of the accident. It is probably less than for real-time PSY2-OPER which positioning error after 5 days was 80 $100 \mathrm{~km}$, but the latter error estimate is a statistic computed on a long period and cannot be directly compared except for consistency considerations. These results are confirmed in the main report of the drift committee of Ollitrault et al. (2010) and PSY2-ZOOM2 and PSY2-AVG results were finally used for the definition of the search zone (blue rectangle in Fig. 1).

The uncertainties of this study are large and legitimised an ensemble approach or at least a global consideration of all results. No individual result could really be discarded on the basis of the observations at hand as they were too scarce or bared large uncertainties themselves. Only the climatology of currents was really discarded on the basis of the analysis of the ocean synoptic flow. In other words, the lack of independent observations uniformly distributed in space and time for the period and for the region of the accident prevented us from making a definitive conclusion, even with the late and precious addition of the fishermen buoys.

The unknown immersion of the drifting objects including the drifting floats (and especially fishermen floats) is another source of uncertainty.

The mesoscale and larger-scale features are satisfactorily well constrained in the ocean model due to the assimilation of SLA and SST satellite observations (Hurlburt et al. 2009). Nevertheless, local unknowns in the reference MDT can lead to spurious current branches, especially in the tropical regions. The MDT improvement is part of the continuous improvement process of the ocean monitoring and forecasting systems assimilating SLA observations.

The bathymetry used by the model (not shown) is a lot smoother than the observed bathymetry of Fig. 1. In the open ocean, currents can interact with the topography and produce eddies or meanders. This is the case of the Mann eddy in the North Atlantic current (Meinen 2001) or of 

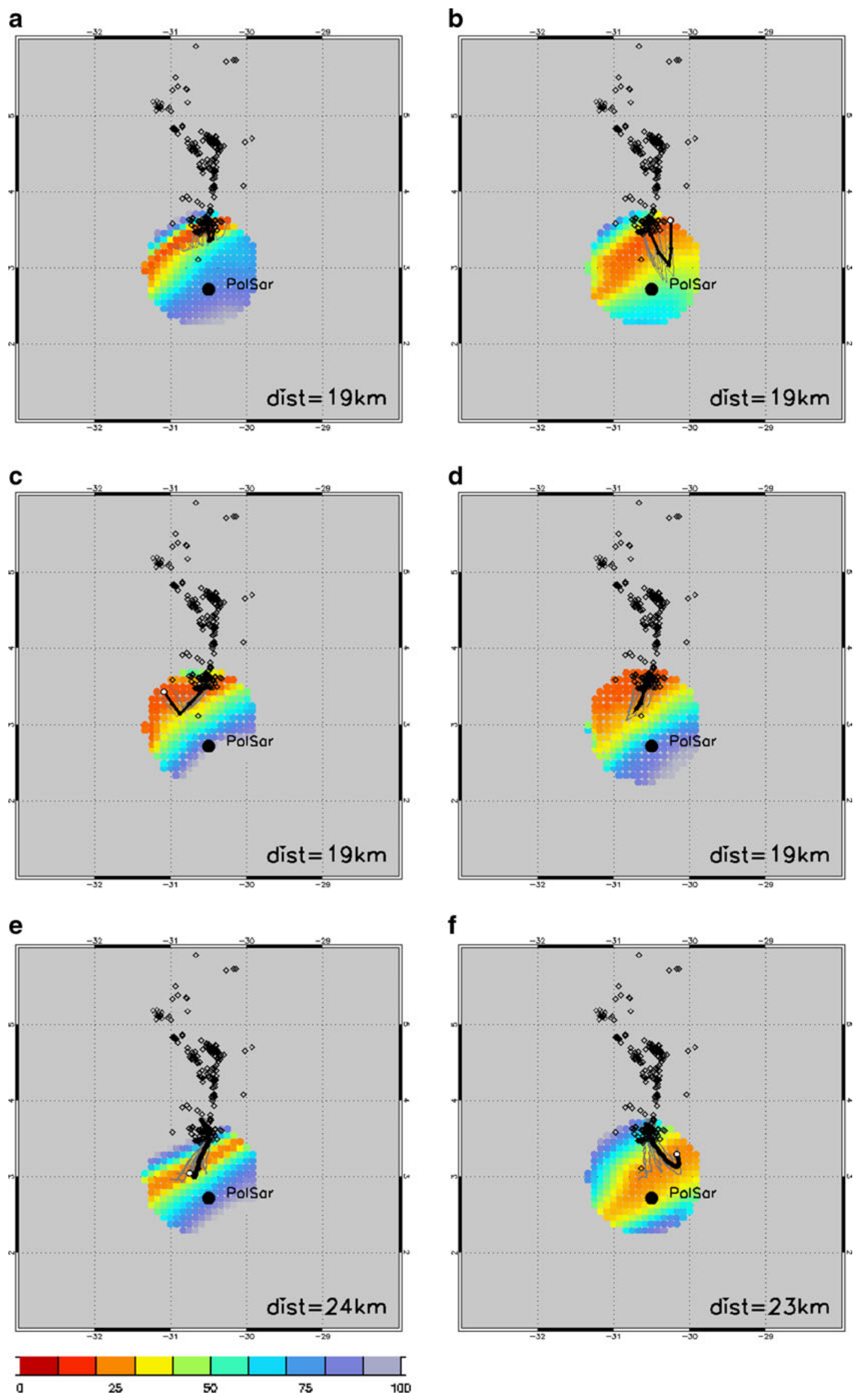
eddies and fronts in the Antarctic Circumpolar Current (Sokolov and Rintoul 2007).

One of the main recommendations from this experience is that in case of accident at sea, it is necessary to launch drifting floats as much as possible on a large-scale zone and as soon as possible after the accident. Satellite survey with synthetic aperture radars should also be programmed.

This work also stresses the need for assimilation of reliable velocity observations in the operational oceanography systems. The Mercator Océan systems should benefit from this update in 2012/2013.

The challenging work of the drift committee and the very tough work for the teams at sea during phase 3 finally lead to no discovery. Hopefully, the wreckage was finally located during a fourth phase of research at sea in 2011. The location of the wreckage was found a few miles North of the LKP, near $3^{\circ} 02^{\prime} \mathrm{N}$ and $30^{\circ} 33^{\prime} \mathrm{W}$. This location did not fall in the consensus small zone indicated by the drift committee but was not inconsistent with the ensemble of results obtained by the drift committee. Had we highlighted the envelope of all probable locations instead of the envelope of mean deterministic locations, the committee would have indicated a much larger zone North-North-west of the LKP including the true position of the wreckage. As this particular zone near the LKP had already been sought with some confidence during the previous phases, the need at that

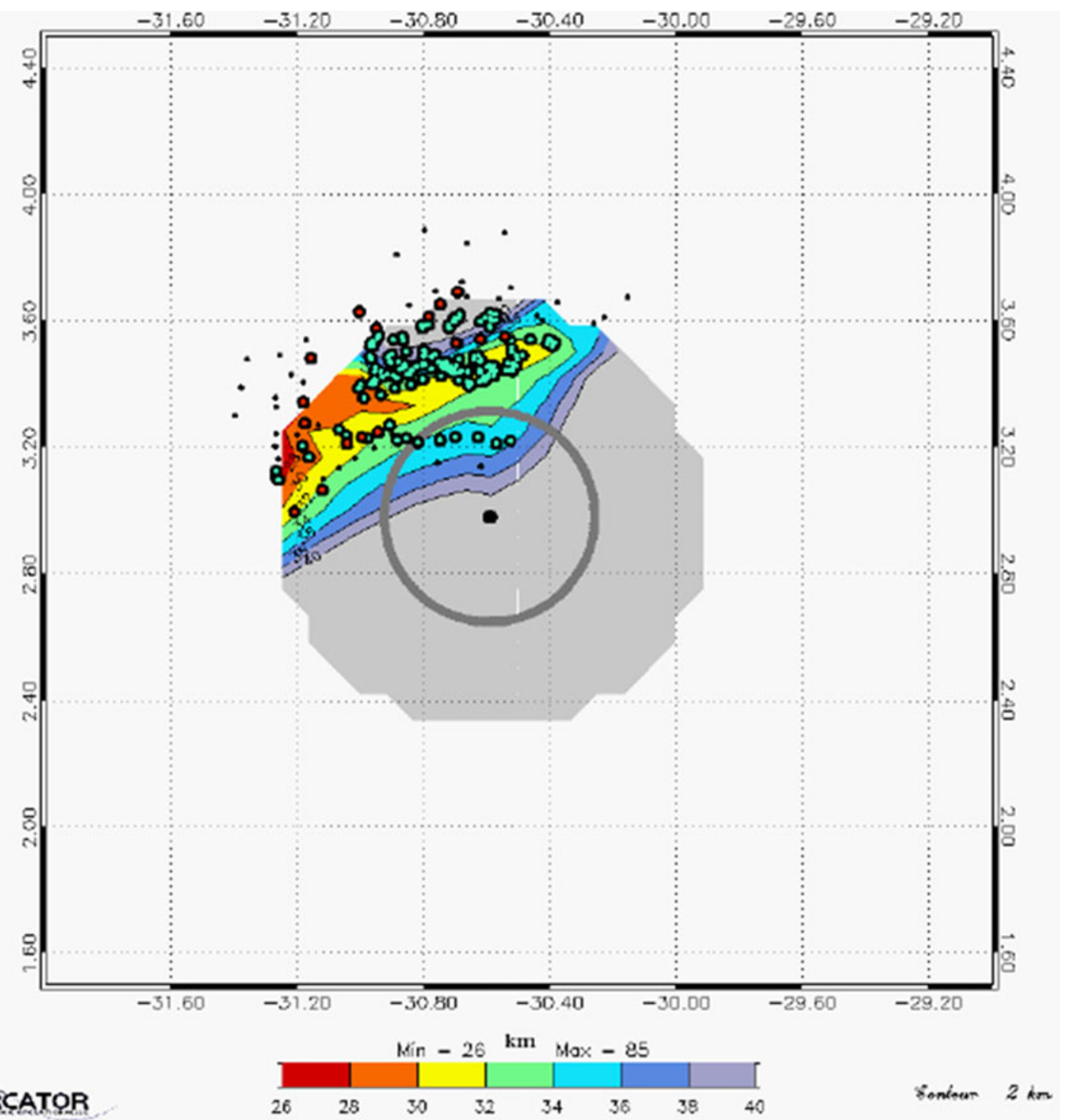

Fig. 9 Inside a 74-km circle, the colour scale stands for the composite of DIST scores from all current estimates with data fitting (only DIST of $<40 \mathrm{~km}$ are shown). The LKP is the thick black point; the $37-\mathrm{km}$ circle is in grey. The thin black points are MOTHY deterministic backward drift estimates of the position of the crash for several bodies and debris; the red bullets are the MOTHY backward drift estimates (for the Vertical Tail Plane only) using the various current estimates (PSY2-REANA, PSY2-ZOOM, SURCOUF, and HYCOM). The green bullets are backward drift estimates of the position of the crash using FVCOM 
time was for a starting point for a new phase of search at sea. Under these circumstances, the strategy was thus to define a small zone for the beginning of the search at sea, knowing that the size of this zone was probably inconsistent with the instrinsic limitations of this work.

Knowing the true position of the wreckage, we can now use this information as an a posteriori consistency check for the various current estimates that were produced. We can assume that the debris stayed in the vicinity of the LKP between 1st and 5th June and drifted from the LKP in the direction of the North, North-east. Under these circumstances, Fig. 8 indicates that without data fitting PSY2-REANA currents produce rather realistic trajectories for the various debris. On the contrary, PSY2-ZOOM2 which was the best current estimate with respect to the available observations shifts the likely zone of the wreckage to the North-east of its actual location. This certainly gave more weight to the Northern part of the 74-km circle when the small research zone was defined. A strong westward current branch near $4^{\circ} \mathrm{N}$ in PSY2-ZOOM2 drove the backward drifts initiated from this latitude to the North-east of the $74-\mathrm{km}$ circle (Fig. 7). Nevertheless, the DIST score using PSY2ZOOM2 (with forward drifts from inside the 74-km circle) consistently indicated the North-North-west of the LKP as a likely location for the wreckage. Finally, the deterministic approach, using reverse drifts and selecting one model against all other models, is not trustworthy in such an under-observed situation. Ensemble and probabilistic approaches, using a variety of current and wind estimates and crossing different analysis viewpoints can bring useful information.

\begin{abstract}
Acknowledgements This work was partly supported by BEA. Many thanks to Pierre Daniel (Météo-France), Eric Dombrowsky (Mercator Océan), Yann Drillet (Mercator Océan), Stéphanie Guinehut (CLS), Julien Negre (Météo-France), Dominique Obaton (Mercator Océan), Charly Régnier (Mercator Océan), Marie-Hélène Rio (CLS), and Marc Tressol (Mercator Océan) for their contribution to this work. The authors also thank the members of the drift committee Michel Ollitrault (IFREMER), Bruno Blanke (CNRS), Changsheng Chen (UMass), Nicolai Diansky (INM RAS), Fabien Lefevre (CLS), Richard Limeburner (WHOI), Pascal Lezaud (IMT), Stéphanie Louazel (SHOM), George Nurser (NOC), Robert Scott (NOC), and Sébastien Travadel (BEA) for this challenging team work and many fruitful interactions. Thanks to the reviewers of the drift committee report Laurent Bertino (NERSC), Fraser Davidson (DFO), Valérie Quiniou (Total), and Carl Wunsh for their support and constructive critics. Thanks to the anonymous reviewers of this article whose constructive comments made the story and results clearer. We finally thank the BEA team and especially Johan Condette and Olivier Ferrante for a very interesting cooperation, and congratulate the researchers at sea for this impressive work.
\end{abstract}

Open Access This article is distributed under the terms of the Creative Commons Attribution License which permits any use, distribution, and reproduction in any medium, provided the original author(s) and the source are credited.

\section{References}

Allen A, Plourde J (1999) Review of leeway: field experiments and implementation. Technical Report CG-D-08-99. US Coast Guard Research and Development Center, Groton, USA

Amante C, Eakins BW (2009) ETOPO1 Arc-minute global relief model: procedures, data sources and analysis, NOAA technical Memorandum NESDIS NGDC-24, 25 pp

Auger L, Bazile E, Berre L, Brousseau P, Bouteloup Y, Bouttier F, Bouyssel F, Descamps L, Desroziers G, Fourrié N, Gérard E, Guidard V, Joly A, Karbou F, Labadie C, Loo C, Masson V, Moll P, Payan C, Piriou J-M, Rabier F, Raynaud L, Rivière O, Seity Y, Sevault E, Taillefer F, Wattrelot E, Yessad K (2010) In: Côté J (ed.) The 2010 upgrades of the Météo-France NWP system. WMO CAS/JSC WGNE Blue Book. Available at: http:// www.wcrp-climate.org/WGNE/BlueBook/2010/documents/ author-list.html

Becker JJ, Sandwell DT, Smith WHF, Braud J, Binder B, Depner J, Fabre D, Factor J, Ingalls S, Kim SH, Ladner R, Marks K, Nelson S, Pharaoh A, Trimmer R, Von Rosenberg J, Wallace G, Weatherall P (2009) Global bathymetry and elevation data at 30 arc seconds resolution: SRTM30_PLUS. Mar Geod 32:355-371. doi:10.1080/ 01490410903297766

Beg Paklar G, Žagar N, Žagar M, Vellore R, Koračin D, Poulain P-M, Orlić M, Vilibić I, Dadić V (2008) Modeling the trajectories of satellite-tracked drifters in the Adriatic Sea during a summertime bora event. J Geophys Res 113:C11S04. doi:10.1029/2007JC004536

Berre L, Pannekoucke O, Desroziers G, Sxtefaňescu SE, Chapnik B, Raynaud L (2007) A variational assimilation ensemble and the spatial filtering of its error covariances: Increase of sample size by local spatial averaging. Proc. ECMWF Workshop on FlowDependent Aspects of Data Assimilation, Reading, United Kingdom, ECMWF, pp 151-168. [Available at http://www.ecmwf.int/ publications/library/do/references/list/14092007]

Blanke B, Delecluse P (1993) Variability of the tropical Atlantic-Ocean simulated by a general-circulation model with 2 different mixedlayer physics. J Phys Oceanogr 23(7):1363-1388

Bleck R (2002) An oceanic general circulation model framed in hybrid isopycnic cartesion coordinates. Ocean Model 4:55-88

Bonjean F, Lagerloef GSE (2002) Diagnostic model and analysis of the surface currents in the tropical Pacific Ocean. J Phys Oceanogr 32:2938-2954. doi:10.1175/1520-0485(2002)032<2938: DMAAOT $>2.0 . \mathrm{CO} ; 2$

Breivik O, Allen A (2008) An operational search and rescue model for the Norwegian Sea and the North Sea. J Mar Syst 69(1-2):99-113

Breivik O, Bekkvik TC, Wettre C, Ommundsen A (2012) BAKTRAK: backtracking drifting objects using an iterative algorithm with a forward trajectory model. Ocean Dyn 62:239-252. doi:10.1007/ s10236-011-0496-2

Chassignet EP, Hurlburt HE, Smedstad OM, Halliwell GR, Hogan PJ, Wallcraft AJ, Bleck R (2006) Ocean prediction with the Hybrid Coordinate Ocean Model (HYCOM). In: Chassignet EP, Verron J (eds) Ocean weather forecasting: an integrated view of oceanography. Springer, Berlin, pp 413-426

Chen C, Malanotte-Rizzoli P, Wei J, Beardsley RC, Lai Z, Xue P, Lyu S, Xu Q, Qi J, Cowles GW (2009) Application and comparison of Kalman filters for coastal ocean problems: an experiment with FVCOM. J Geophys Res 114:C05011. doi:10.1029/ 2007JC004548

Chen C, Limeburner R, Gao G, Xu Q, Qi J, Xue P, Lai Z, Lin H, Beardsley R, Owens B, Carlson B (2012) FVCOM model estimate of the location of Air France 447. Ocean Dyn. doi:10.1007/ s10236-012-0537-5

Cummings J, Bertino L, Brasseur P, Fukumori I, Kamachi M, Martin MJ, Mogensen K, Oke P, Testut CE, Verron J, Weaver A (2009) 
Ocean Data Assimilation Systems for GODAE. Oceanography 22 (3):96-109

Dai A, Trenberth K (2002) Estimates of freshwater discharge from continents: latitudinal and seasonal variations. J Hydrometeorol 3 (6):660-687

Daniel P, Jan G, Cabioc'h F, Landau Y, Loiseau E (2002) Drift modeling of cargo containers. Spill Sci Technol Bull 7(5-6):279-288

Dombrowsky E, Bertino L, Brassington GB, Chassignet EP, Davidson F, Hurlburt HE, Kamachi M, Lee T, Martin MJ, Mei S, Tonani M (2009) GODAE systems in operation. Oceanography 22(3):80-95

Egbert GD, Erofeeva SY (2002) Efficient inverse modeling of barotropic ocean tides. J Atmos Ocean Technol 19:183-204. doi:10.1175/1520-0426(2002)019<0183:EIMOBO>2.0.CO;2

Elliott AJ (2004) A probabilistic description of the wind over Liverpool Bay with application to oil spill simulations. Estuarine Coastal Shelf Sci 61:569-581

Goosse H, Campin J-M, Deleersnijder E, Fichefet T, Mathieu P-P, Maqueda MAM, Tartinville B (2001) Description of the CLIO model version 3.0. Institut d'Astronomie et de Geophysique Georges Lemaitre, Catholic University of Louvain, Belgium

Gould J, Roemmich D, Wijffels S, Freeland H, Ignaszewsky M, Jianping X, Pouliquen S, Desaubies Y, Send U, Radhakrishnan K, Takeuchi K, Kim K, Danchenkov M, Sutton P, King B, Owens B, RiserGould S (2004) Argo profiling floats bring new era of in situ ocean observations. Eos Trans Amer Geophys Union 85(19). doi:10.1029/2004EO190002

Grodsky SA, Lumpkin R, Carton JA (2011) Spurious trends in global surface drifter currents. Geophys Res Lett 38(L10606). doi:10.1029/2011GL047393

Hayden CM, Purser RJ (1995) Recursive filter objective analysis of meteorological fields: applications to NESDIS operational processing. J Appl Meteorol 34(1):3-15

Hurlburt HE, Brassington GB, Drillet Y, Kamachi M, Benkiran M, Bourdallé-Badie R, Chassignet EP, Jacobs GA, Le Galloudec O, Lellouche J-M, Metzger EJ, Oke PR, Pugh TF, Schiller A, Smedstad OM, Tranchant B, Tsujino H, Usui N, Wallcraft AJ (2009) Highresolution global and basin-scale ocean analyses and forecasts. Oceanography 22(3):110-127. doi:10.5670/oceanog.2009.70

Jackett DR, Mcdougall TJ (1995) Minimal adjustment of hydrographic profiles to achieve static stability. J Atmos Oceanic Technol 12:381-389. doi:10.1175/1520-0426(1995)012<0381: MAOHPT $>2.0 . \mathrm{CO} ; 2$

Law Chune S., (2012) Apport de l'océanographie opérationnelle à l'amélioration de la prévision de la dérive océanique dans le cadre d'opérations de recherche et de sauvetage en mer et de lutte contre les pollutions marines. Ph.D. thesis, Université Paul Sabatier, Toulouse

Leonard B (1979) Stable and accurate convective modeling procedure based on quadratic upstream interpolation. Comput Methods Appl Mech Eng 19(1):59-98

Leonard BP (1991) The ULTIMATE conservative difference scheme applied to unsteady one-dimensional advection. Comp Methods Appl Mech Engrg 88:17-74

Levitus S, Boyer TP, Conkright ME, O’Brien T, Antonov J, Stephens C, Stathoplos L, Johnson D, Gelfeld R (1998) NOAA Atlas NESDIS 18, WORLD OCEAN DATABASE 1998: Vol. 1: Introduction. U.S. Govt. Print. Off, Washington, p 346

Lumpkin R, Pazos M (2006) Measuring surface currents with Surface Velocity Program drifters: the instrument, its data, and some recent results. In: Griffa A, Kirwan AD, Mariano AJ, Ozgokmen $\mathrm{T}$, Rossby $\mathrm{T}$ (eds) Chapter two of Lagrangian analysis and prediction of coastal and ocean dynamics (LAPCOD). Cambridge University Press, Cambridge

Madec G (2008) "NEMO ocean engine". Note du Pole de modélisation, Institut Pierre-Simon Laplace (IPSL), France, No 27 ISSN No 1288-1619. Available at: http://www.nemo-ocean.eu/content/ download/15482/73217/file/NEMO_book_v3_3.pdf

Meinen CS (2001) Structure of the North Atlantic current in streamcoordinates and the circulation in the Newfoundland basin. Deep Sea Res I 48:1553-1580

O’Donnell J, Ullman D, Spaulding M, Howlett E, Fake T, Hall P, Isaji T, Edwards C, Anderson E, McClay T, Kohut J, Allen A, Lester S, Turner C, Lewandowski M (2005) Integration of Coastal Ocean Dynamics Application Radar (CODAR) and Short-Term Predictive System (STPS) Surface Current Estimates into the Search and Rescue Optimal Planning System (SAROPS). U.S. Coast Guard Research and Development Center, Report \# CG-D-01-2006. Available at: http://www.dtic.mil/cgi-bin/GetTRDoc? $\mathrm{AD}=\mathrm{ADA} 444766 \&$ Location $=\mathrm{U} 2 \& \mathrm{doc}=$ GetTRDoc.pdf

Ollitrault M, Blanke B, Chen C, Diansky N, Drévillon M,Greiner E, Lefevre F, Limeburner R, Lezaud P, Louazel S, Nurser G, Paradis D, Scott R (2010) Estimating the wreckage location of the Rio-Paris AF447, BEA report. Available at: http:/www.bea.aero/en/enquetes/ flight.af.447/phase3.search.zone.determination.working.group. report.pdf

Payan C (2008) Status on the use of scatterometer data at Meteo France. In: International Winds Workshop Proceedings (IWW9), Annapolis, MD, USA, 14-18 April 2008

Payan C (2010) Improvements in the use of scatterometer winds in the operational NWP System at Meteo France. In: International Winds Workshop Proceedings (IWW10), Tokyo, Japan, 22-26 February 2010

Pham DT, Verron J, Roubaud MC (1998) A singular evolutive extended Kalman filter for data assimilation in oceanography. J Mar Syst 16(3-4):323-340

Poon YK, Madsen OS (1991) A two layers wind-driven coastal circulation model. J Geophys Res 96(C2):2535-2548

Portabella M, Stoffelen A (2001) Rain detection and quality control of seawinds. J Atm Ocean Tech 18:1171-1183

Rio MH, Schaeffer P, Hernandez F, Lemoine J-M (2005) The estimation of the ocean Mean Dynamic Topography through the combination of altimetric data, in-situ measurements and GRACE geoid: from the global to regional studies. In: Proceedings from the GOCINA international workshop, Luxembourg

Saunders RW, Matricardi M, Geer A, Bayer P, Embury O, Merchant C (2010) RTTOV-9 science and validation report. NWPSAF-MOTV-020, 74 pp

Scott RB, Ferry N, Drévillon M, Barron CN, Jourdain NC, Lellouche J-M, Metzger EJ, Rio M-H, Smedstad OM (2012) Estimates of surface drifter trajectories in the Equatorial Atlantic: a multimodel ensemble approach. Ocean Dyn, SAR Spec Issue 62 (7):1091-1109. doi:10.1007/s10236-012-0548-2

Sokolov S, Rintoul SR (2007) On the relationship between fronts of the Antarctic Circumpolar Current and surface chlorophyll concentrations in the Southern Ocean. J Geophys Res 112:C07030. doi:10.1029/2006JC004072

Tranchant B, Testut CE, Renault L, Ferry N, Birol F, Brasseur P (2008) Expected impact of the future SMOS and Aquarius Ocean surface salinity missions in the Mercator Océan operational systems: new perspectives to monitor ocean circulation. Remote Sens Environ 112:1476-1487

Zalesak ST (1979) Fully multidimensional flux-corrected transport algorithms for fluids. J Comput Phys 31(3):335-362 